\title{
INTRASPECIFIC VARIATION IN PLANT-PLANT INTERACTIONS AND BELOWGROUND ZONE OF INFLUENCE OF BIG SAGEBRUSH (Artemisia \\ tridentata)
}

by

Andrii Zaiats

\author{
A thesis \\ submitted in partial fulfillment \\ of the requirements for the degree of \\ Master of Science in Biology \\ Boise State University
}

May 2019 
(C) 2019

Andrii Zaiats

ALL RIGHTS RESERVED 


\title{
BOISE STATE UNIVERSITY GRADUATE COLLEGE
}

\section{DEFENSE COMMITTEE AND FINAL READING APPROVALS}

of the thesis submitted by

\begin{abstract}
Andrii Zaiats
Thesis Title: Intraspecific Variation in Plant-Plant Interactions and Belowground Zone of Influence of Big Sagebrush (Artemisia tridentata)
\end{abstract}

Date of Final Oral Examination: $\quad 25$ February 2019

The following individuals read and discussed the thesis submitted by student Andrii Zaiats, and they evaluated his presentation and response to questions during the final oral examination. They found that the student passed the final oral examination.

Trevor T. Caughlin, Ph.D. Chair, Supervisory Committee

Matthew Germino, Ph.D. Member, Supervisory Committee

Marcelo Serpe, Ph.D. Member, Supervisory Committee

The final reading approval of the thesis was granted by Trevor Caughlin, Ph.D., Chair of the Supervisory Committee. The thesis was approved by the Graduate College. 


\begin{abstract}
Post-fire restoration of degraded sagebrush ecosystems over large areas of the Great Basin is challenging, in part due to unpredictable outcomes. Low rates of restoration success are attributed to increasing frequencies of wildfires, biological invasions, and climate variability. Quantifying restoration outcomes by accounting for sources of biotic and abiotic variability will improve restoration as a predictive science. One source of biotic variability is neighbor interactions, which can regulate demographic parameters of coexisting species and are an important determinant of community structure, ecosystem functions, and population dynamics. Our objective was to quantify how intraspecific variability in big sagebrush, Artemisia tridentata, including three subspecies and two ploidy levels, is related to subspecies' reaction to conspecific neighbor presence. Neighbor interactions can alter population growth rate via competition or facilitation depending on specific environmental conditions. Using a longterm common garden experiment, we developed spatially-explicit hierarchical models to quantify the effects of size-structured crowding on plant growth and survival. We found that neighbor interactions can vary significantly over time and space, and tend to be more pronounced under wetter and cooler climate conditions. We further tested if water availability, one of the major limiting factors in arid ecosystems, can underlie competitive interactions in a common garden, including density dependence. We used a deuteriumtracer experiment to quantify belowground zone of influence and crowding effect on plant water uptake. The results suggest that intraspecific variability in lateral root extent
\end{abstract}


may be linked to subspecies identity and ploidy level. We did not find strong evidence that neighbor presence and size can alter water uptake from a shallow soil horizon, potentially suggesting size-independent partitioning of water resources between neighboring plants. We further hypothesize that variability in root architecture may reflect an axis for ecohydrological niche segregation contributing to the process of plant coexistence and evolution in heterogeneous landscapes. Our study complements previous knowledge of belowground processes in big sagebrush populations, including patterns of resource acquisition, and indicates promising avenues for further research of the ecology and evolution of this species. The results highlight how local plant-plant interactions can be a source of variation in common garden experiments, which are used to evaluate adaptive capacity and seed transfer zone development for A. tridentata populations. Potential applications of our work include planting density recommendations for big sagebrush in applied and experimental contexts, and provide mechanistic understanding of intraspecific diversification and ecological tradeoffs related to local adaptations. 
TABLE OF CONTENTS

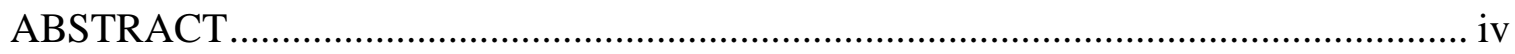

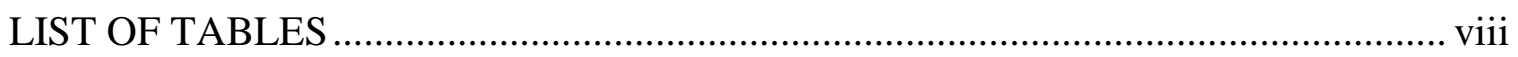

LIST OF FIGURES …………………………………...................................... ix

CHAPTER ONE: INTRASPECIFIC VARIATION IN PLANT-PLANT

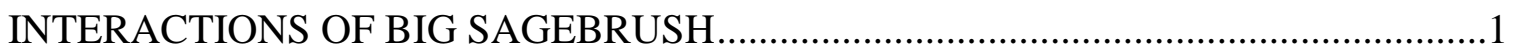

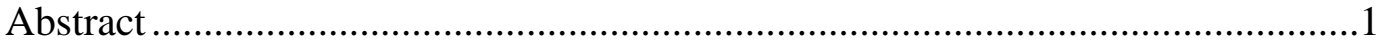

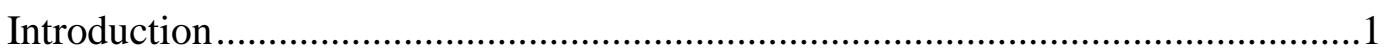

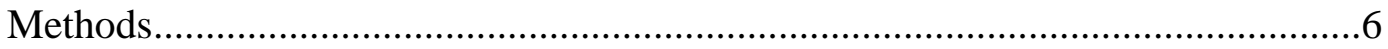

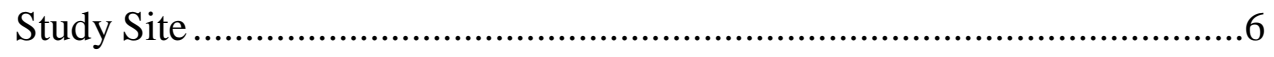

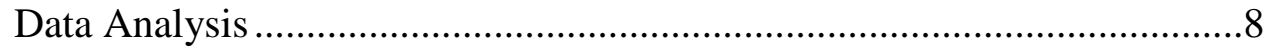

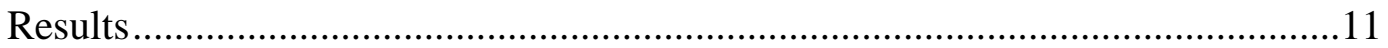

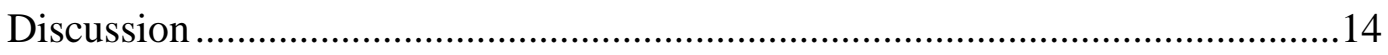

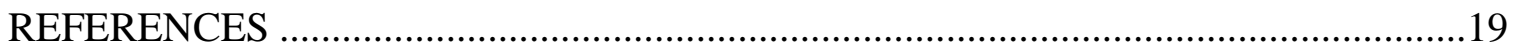

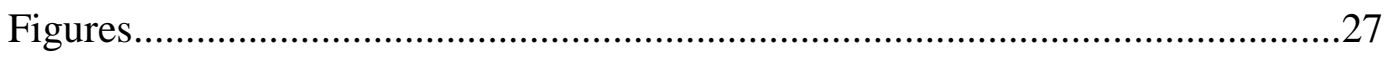

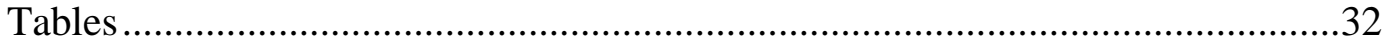

CHAPTER TWO: QUANTIFYING INTRASPECIFIC VARIABILITY IN BIG

SAGEBRUSH LATERAL ROOT EXTENT AND FUNCTIONING USING A

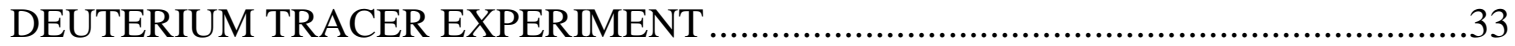

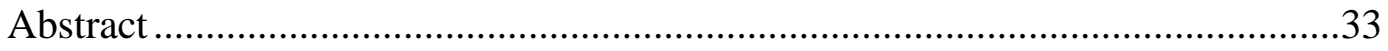

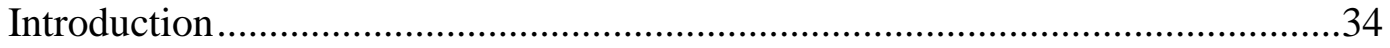

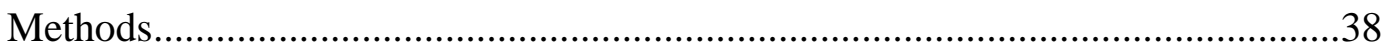


Site Description...........................................................................

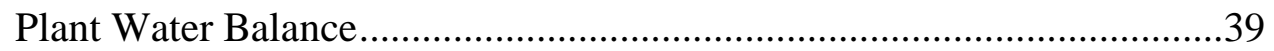

Deuterium Labeling ..................................................................40

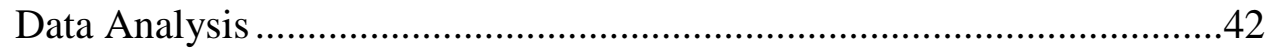

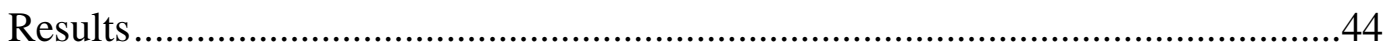

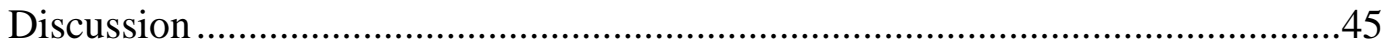

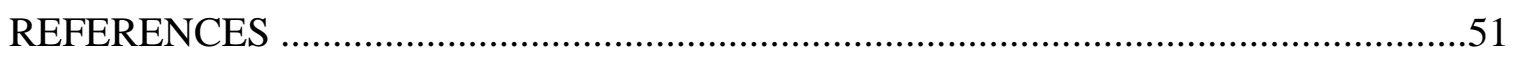

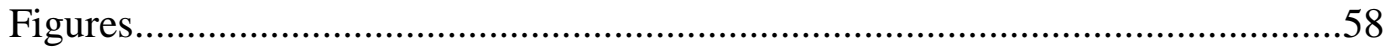

Tables .................................................................................................. 64

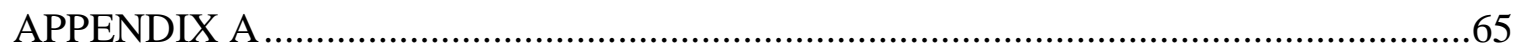

Supplementary Figures: Chapter One ...................................................65

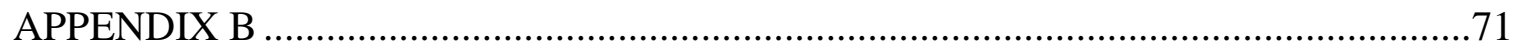

Supplementary Figures: Chapter Two ….................................................. 71 


\section{LIST OF TABLES}

Table 1: Annual climate data for three common gardens during the experiment

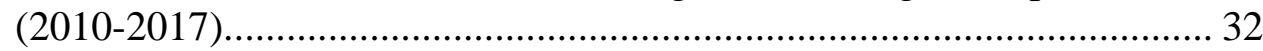

Table 2: Model evaluation comparing the fit of linear and non-linear regressions of

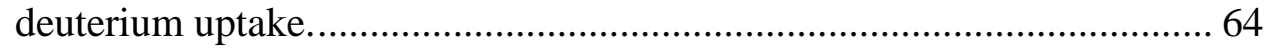




\section{LIST OF FIGURES}

Figure 1: Posterior samples representing the relationship between the growth in isolation and crowding effect in three A. tridentata common gardens during the 2011 census interval. The y axis represents the change to growth in isolation when the crowding effect is increased by $2 \mathrm{SD}$. The symbols show the medians of estimated parameters and the error bars

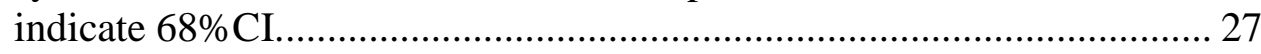

Figure 2: $\quad$ Posterior samples representing the relationship between the growth in isolation and crowding effect in two A. tridentata common gardens during the 2018 census interval. The y axis represents the change to growth in isolation when the crowding effect is increased by $2 \mathrm{SD}$. The symbols show the medians of estimated parameters and the error bars indicate $68 \% \mathrm{CI}$.

Figure 3: Posterior samples that represent the crowding effect on the relative growth rates (RGR) of $A$. tridentata in three common gardens using 2011 census interval. Thick lines represent $80 \% \mathrm{CI}$, while thinner lines indicate 95\% CI. The $\mathrm{x}$ axis shows five subspecies:cytotype groups of $A$. tridentata. The effect size corresponds to the change in RGR in isolation when crowding is increased by 2SD. Values of zero indicate no crowding effect on RGR.

Figure 4: $\quad$ Posterior samples that represent the effect of crowding on survival probability in A. tridentata in two common gardens. The effect sizes are based on census interval between 2012 and 2018. Thick lines show $80 \% \mathrm{CI}$, while thinner lines indicate $95 \% \mathrm{CI}$. Coefficients indicate the change to survival in isolation when crowding is increased by $2 \mathrm{SD}$, and values of zero indicate no crowding effect.

Figure 5: The rate of decline of crowding effect with distance in Majors Flat common garden during 2011 growth season for A.t. tridentata:2x. The black line corresponds to the median crowding effect, and the shaded area to the $1 \mathrm{SD}$. The y axis represents growth in isolation decline of the target plant under the presence of an average neighbor.

Figure 6: A diagram of an experimental unit in Orchard common garden. The centroid of the plot is a location where deuterium enriched water was introduced, the gray points show the grid of plants, and the arrows indicate a distance of each plant to the source location. 58 
Figure 7: $\quad$ Water status of $A$. tridentata plants in Orchard common garden during the deuterium tracer experiment. The values are shown for pre-dawn and midday leaf water potential measurements for five different subspecies:cytotype groups of big sagebrush. Lower values represent higher water stress

Figure 8: $\quad$ A. tridentata uptake of deuterium $\left({ }^{2} \mathrm{H}_{2} \mathrm{O}\right)$ enriched water as a function of distance from the source location and plant size. The label was introduced into plant interspaces in Orchard common garden in Spring 2018. The vertical axis indicates the change in deuterium ratio between the pre- and post-treatment. Different colors indicate subspecies:cytotype identity of big sagebrush, and the gray areas represent one SD around the posterior mean.

Figure 9: $\quad$ Posterior distribution of the average deuterium uptake by a target plant (upper plate). The lower plate shows the crowding effect on the label uptake in isolation under 2 SD increase in crowding ratio. The categories correspond to three subspecies of $A$. tridentata (tridentata, vaseyana, and wyomingensis)

Figure 10: A line plot representing soil volumetric moisture readings at three soil depths over the period of one month preceding the labeling experiment. The vertical dashed line indicates the day of deuterium addition.

Figure 11: $\quad$ Predicted belowground zone of influence of $A$. tridentata subspecies:cytotype groups in Orchard common garden. The figures correspond to deuterium content where higher colour intensity indicates higher water uptake from shallow $5-25 \mathrm{~cm}$ soil horizon. Projections $<0.9$ $\mathrm{m}$ were excluded (empty centers) due to out of range model predictions. 63

Figure S1: An empirical cumulative density function (ECDF) plot showing the distribution of relative growth rate (RGR) of A. tridentata in three common gardens. The RGR is calculated using 2011 census interval for all three sites (Orchard, Majors Flat, and Ephraim), and 2018 census interval for Orchard Majors Flat sites. The RGR is scaled to a monthly time step, and each point represents an individual plant. 66

Figure S2: $\quad$ Posterior samples representing the intrinsic relative growth rates of $A$. tridentata in three common gardens. Thick lines represent $80 \% \mathrm{CI}$, thinner lines indicate $95 \% \mathrm{CI}$, and the dots are the medians of the posterior distributions. The categories on the $\mathrm{x}$ axis represent five analyzed subspecies:cytotype groups of $A$. tridentata.

Figure S3: $\quad$ Posterior samples that represent the intrinsic probability of survival of $A$. tridentata in Orchard and Major Flats common gardens, using the census interval between 2012 and 2018. The $\mathrm{x}$ axis represents five subspecific 
categories of $A$. tridentata. Thick lines represent $80 \% \mathrm{CI}$, while thinner lines indicate $95 \% \mathrm{CI}$, and the dots are the medians of the posterior samples.

Figure S4: Posterior samples that represent the crowding effect on the relative growth rates of $A$. tridentata in two common gardens using 2018 census interval. Thick lines represent $80 \% \mathrm{CI}$, while thinner lines indicate $95 \% \mathrm{CI}$, and the dots are the medians of the posterior samples. The $\mathrm{x}$ axis represents five subspecies:cytotype groups of $A$. tridentata. The effect size corresponds to the change in RGR when the calculated competitive pressure increases by 2 SD. Values of zero correspond to the change in RGR of a target plant under the average competitive pressure.

Figure S5: Mapped competition effect on A.t. tridentata:2x in Majors Flat common garden based on 2011 census interval. Dark colors indicate higher predicted competition effect, and the dots represent sagebrush plants with the relative crown size corresponding to the size of a point. The axes show $\mathrm{x}$ and $\mathrm{y}$ coordinates in meters 70

Figure S6: Big sagebrush (Artemisia tridentata) in Orchard common garden, ID. The photograph shows the spatial arrangement and individual variation in size and survival of $A$. tridentata.

Figure S7: A box plot showing crown size distribution of A. tridentata in Orchard common garden. Measurements represent the data collected in summer 2018. The original crown dimensions were transformed to crown volume. The actual data points (pink dots) are jittered over the standard boxplots.

Figure S8: $\quad$ A box plot indicating deuterium uptake by big sagebrush individuals in Orchard common garden. The label uptake is calculated as the difference between the pre- and post-treatment deuterium measurements, and is shown for five subspecies:cytotype categories. The actual data points (pink dots) are jittered over the standard boxplots.

Figure S9: A box plot indicating deuterium uptake by three subspecies of big sagebrush in Orchard common garden. The uptake is calculated as the difference between the pre- and post-treatment deuterium measurements. The actual data points (pink dots) are jittered over the standard boxplots. 


\title{
CHAPTER ONE: INTRASPECIFIC VARIATION IN PLANT-PLANT INTERACTIONS OF BIG SAGEBRUSH
}

\begin{abstract}
Species coexistence and neighbor interactions are critical factors in structuring plant communities, maintaining species diversity and ecosystem functions. Intraspecific variability, including genome duplication and local adaptations can contribute to variation in demographic rates, stress tolerance, and neighbor interactions. Using a longterm common garden experiment, we applied spatially-explicit neighborhood models to quantify differential effects of crowding on growth and survival of Artemisia tridentata, including three subspecies and two ploidy levels. Our results suggest that intraspecific patterns in competition effect on growth are more pronounced during the early stage of stand development, and dissipate as the plants mature. We also found evidence of facilitation as neighbor presence differentially increased the probability of plant survival. In general, neighbor effects were more pronounced in sites with higher precipitation and cooler temperature regimes. Our findings generally agree with the stress-gradient hypothesis, and provide experimental evidence for intraspecific variation in plant-plant interactions.
\end{abstract}

\section{Introduction}

Non-trophic interactions between neighboring plants are a key driver of plant community structure and population dynamics (Adams et al., 2013; Canham and Uriarte, 2006; Wright et al., 2014). The relative strength of interactions between conspecific vs. 
heterospecific plant neighbors plays a critical role in theories for species coexistence (Barabás et al., 2018; Chesson, 2018, 2000). Within single-species populations, negative density dependence is an important determinant of spatial and temporal dynamics (Law et al., 2003). Interactions between conspecific neighbors also underlie conservation and restoration outcomes, including tree species extinction after seed disperser loss (Caughlin et al., 2015), forest plantation biomass after thinning (Simard and Sachs, 2004), and plant reintroduction success in degraded sites where nurse plants facilitate establishment (Zhao et al., 2007). Most studies of interactions between plant neighbors have considered differences at the species-level (but see Bennett et al., 2016; Hart et al., 2016; Shao et al., 2018; Uriarte and Menge, 2018). However, many plant species have considerable intraspecific variation, including life strategy, local adaptation, and ploidy variation (Bonham et al., 1991; Shryock et al., 2014; Wood et al., 2009). How intraspecific variation alters the outcomes of interaction between neighboring plants remains an unanswered question with consequences for ecology, evolution, and conservation.

Local adaptations in physiological and morphological traits are one source of intraspecific variability with potential to impact plant-plant interactions (Lind et al., 2017; Shryock et al., 2015). Population-specific adaptive traits can lead to speciation (Münzbergová and Haisel, 2018; Rieseberg and Willis, 2007), and this process can be mediated by spatial plant-plant interactions (Rodriguez et al., 1996). Biotic interactions, including intraspecific facilitation, are likely to be important in evolutionary processes such as genetic diversification and species maintenance (Calama et al., 2019; Currie et al., 2004; Moya-Larano, 2010) Intraspecific interactions within heterogeneous species may be a subject to environmental effects, indicating, for example, the applicability of 
stress-gradient hypothesis (Maestre et al., 2009). Humphrey and Pyke (1998) investigated the effects of intraspecific variation in growth strategies of a rhizomatous grass species revealing a competitive advantage of one species over another when resource availability increased. A few studies have asked how individual-level trait values impact plant competition (Shao et al., 2018; Umaña et al., 2018), but we lack empirical evidence of how conspecific biotic interactions operate in natural communities, change in space and time, and allow for genetically distinct populations to coexist.

Another key component of intraspecific variability in plant populations is variation in ploidy level, the number of sets of homologous chromosomes per cell. This variation is common among vascular plants including intraspecific ploidy variation (Wood et al., 2009). Polyploidy can impact plant vital rates (Groot et al., 2012) and competitive interactions (Petrone Mendoza et al., 2018). Neighbor interactions along polyploid hybrid zones are believed to be one of the key factors in polyploid establishment (Petit et al., 1999). Despite the spatial nature of neighbor interactions, few studies have adopted an explicitly spatial approach to quantify plant-plant interactions in polyploidy hybrid zones (Li et al., 2004; Rodriguez, 1996). Intraspecific variation in competitive abilities is a common outcome of intraspecific ploidy variation (Čertner et al., 2019; Maceira et al., 1993), however, understanding this variation becomes critical in context of landscape population dynamics and population persistence.

In a changing world, non-local genotypes will be more likely to interact with local genotypes, due to factors such as climate-induced shifts in range boundaries (Davis and Shaw, 2001), plant invasion (Schlaepfer et al., 2010), and restoration projects (Germino et al., 2018; Havens et al., 2015). Given potential consequences of interactions between 
genotypes for eco-evolutionary dynamics, understanding demographic outcomes when non-local genetic material is introduced to novel environments is of paramount importance. However, predicting the demographic success of plant genotypes under novel competitive regimes (e.g., Leger, 2008) is complicated because plant-plant interactions are likely to change over the course of stand development. Because smaller individuals are more susceptible to asymmetric competition than larger individuals, the effects of slight size differences during initial establishment tend to be compounded over time (DeMalach et al., 2016; Werner et al., 2016). Alternatively, plant-plant interactions may switch from facilitation to competition as nurse plants initially facilitate seedling establishment and then eventually compete with new recruits (Maestre et al., 2009; Miriti, 2006). At the same time as individual size changes during plant establishment, stand-level characteristics change as well. These changes could have consequences for plant-plant interactions as self-thinning during the initial stages of stand development leaves individuals relatively insensitive to competition in lower densities, thereby decreasing competition processes (Yastrebov, 1996). Altogether, we expect that in the environments with mixed conspecific genotypes, interactions between neighbors will have important consequences for ecology and evolution of plant populations (Havens et al., 2015). Because plant-plant interactions are likely to change over time during individual and stand development (Schwinning and Weiner, 1998), quantifying these interactions at multiple time points will be necessary. However, studies that have examined plant-plant interactions over time as the stand develops are rare.

Big sagebrush, Artemisia tridentata Nutt., represents an ideal study species to quantify impact of intraspecific variation on plant-plant interactions. This perennial shrub 
is locally adapted to a wide range of soil and climatic conditions across western North America and exhibits high levels of genetic diversity within species (McArthur et al., 1981; Richardson and Chaney, 2018). A combination of morphological and ecological differences has led to the recognition of three wide-spread subspecies (Shultz, 2009). Additionally, A. tridentata is characterized by high frequencies of polyploidy (from hereon cytotypes) with multiple evolutionary origins (Richardson et al., 2012). Accounting for local adaptation in genetically-diverse A. tridentata populations is an increasingly important component of regional restoration projects (Miglia et al., 2005). Ecological restoration in the Great Basin is often aimed at recovering A. tridentata populations following wild fires. These attempts are conducted with seeds or seedlings that originate from natural, but not necessarily local, populations or plant nurseries (Germino et al., 2018; Mahalovich and McArthur, 2005). Altogether, understanding how novel combinations of genetically different populations of A. tridentata plants interact has direct application to restoring the imperiled sagebrush steppe ecosystem.

We quantified how plant-plant interactions impact demographic rates, growth, and survival between individuals that represent a range-wide intraspecific diversity of $A$. tridentata. Our study represents data from plots in a common garden experiment, including repeated censuses on >1300 individual plants, representing 55 source seed locations, three subspecies, and two ploidy levels. Because experimental plots were distributed at a regional-scale spanning a wide range of environmental conditions and monitored for eight years, we were able to quantify how spatial and temporal variation impacts plant-plant interactions. Using these experimental data, we parameterized spatially-explicit models for growth and survival to test the following hypotheses: (i) 
Subspecies with higher growth rates will be more sensitive to competition compared to slow growing subspecies, and polyploids will be less affected compared to diploid cytotypes; (ii) Neighbor competition will increase as environmental conditions become more favorable; (iii) Local intraspecific competition will be weaker early in stand development and will intensify as the stand develops.

\section{Methods}

\section{$\underline{\text { Study Site }}$}

Our study includes three experimental common gardens established in 2010. The three locations represent an environmental gradient of precipitation and temperature (Chaney et al., 2017). The gardens were established between April and June 2010, when 468-470 seedlings were outplanted in each garden. Growth and survival were monitored for the first two years after establishment and were resumed five years later in the Orchard and Majors Flat gardens, while the Ephraim common garden was terminated due to logistical difficulties in maintenance. Plant size was measured during early development in 2011 in Orchard $(n=419)$, Majors Flat $(n=448)$, and Ephraim $(n=434)$; late development growth during 2018 in Orchard $(n=255)$ and Majors Flat $(n=368)$. The survival data set includes the time period between 2012 and 2018 in Orchard $(n=421)$, and Majors Flat $(\mathrm{n}=448)$.

All three common gardens include plants of three commonly recognized subspecies and five subspecies:cytotypes groups: A.t. tridentata:2x, A.t. tridentata:4x, A.t. vaseyana:2x, A.t. vaseyana:4x, and A.t. wyomingensis:4x. The seeds were sourced from 55 different populations across the arid west (Chaney et al., 2017). While initial trials included individuals of A. arbuscula, very few plants of this species survived and 
we did not include these individuals in our analyses. We grouped individuals of $A$. tridentata into five groups, representing different combinations of subspecies and cytotypes. Plants within each garden were organized in a grid with $1 \mathrm{~m}$ and $1.5 \mathrm{~m}$ spacing on two axes respectively. To analyze spatial interactions between the individuals, we calculated a distance matrix, including pairwise distances between all plants in each common garden. Based on previous work, we expected no direct effect from neighbors beyond a four-meter distance, and, therefore, considered plant neighbors in a radius of $<4$ $\mathrm{m}$ from target plants (Sturges, 1977).

We transformed the measurements of height and width into a crown volume using a standard formula for ellipsoid volume $\operatorname{Siz}_{i}=4\left(a_{i} b_{i}{ }^{2} \pi\right) / 3$, assuming that plants are circular in shape with radius $b$ and height $a$. We calculated plant growth for each census interval as a change in crown volume from $t$ to $t+1, g_{t}=$ Size $_{t}-$ Size $_{t-1}$. To increase the comparability between our models, we subset and partitioned our data set into two census intervals for growth: (i) the growth season of 2011 (second year) for all three sites, where we observed active growth of establishing plants; and (ii) the growth season of 2018 (ninth year) for Orchard and Majors Flat. We converted the observed values to a relative growth rate on a monthly interval scale. The early census interval includes an entire year in Majors Flat and Ephraim gardens, and only growing season (Spring-Fall) in Orchard. The second census interval captures the growing season both in Orchard and Majors Flat. Although there is a discrepancy in time scale between census intervals, A. tridentata is a species that has vegetative growth mainly during the spring and summer (Evans et al., 1991; Evans and Black, 1993). This period of active growth was captured in all of our census intervals, which made our results comparable. For survival, we analyzed a long- 
term interval for Orchard (five) and Majors Flat (six years) to capture a high number of mortalities while excluding the initial two years of growth when mortality due to density independent factors is more likely.

\section{Data Analysis}

The goal of our statistical model was to quantify the effect of neighbors (i.e., crowding effect) on growth and survival of plants in three common gardens across census intervals. The crowding effect represents a quantitative measure and impact of local neighborhoods on each target plant and allows for positive and negative modes of neighbor effect (Canham and Uriarte, 2006). We fit hierarchical Bayesian models for each site, census interval, and vital rate, resulting in a total of seven models. We decided to fit separate models, rather than pooling all data together in a single model, based on our expectation that growth and survival are likely to vary widely between sites and census intervals. For all models, we included random effects of intraspecific groups, enabling shared variance between subspecies:cytotype levels (Gelman and Hill, 2006).

We modeled plant growth as a function of subspecies:cytotype levels, target plant size, and crowding effects. Crowding was modeled as a non-linear function that depends on the size of a neighbor, as well as its distance from the target plant. We described the non-linear effect of crowding with a modified negative exponential function:

$$
W_{i, s}=\sum_{j=1, j \neq i}^{n} c_{[s]} \operatorname{Size}_{j, s} e^{-b D_{j}^{2}}
$$

where $W$ is a cumulative crowding effect experienced by plant $i$ belonging to subspecies:cytotype group $s$, Size is the crown volume of neighbor $j, b$ is the scaling factor that determines the rate of decline in effect with distance, $D$, from neighbor $j$ to 
target plant $i$. Parameter $c_{[s]}$ estimates the contribution of each subspecies:cytotype group to the crowding term as a normally-distributed random effect. Similar spatial models have been successfully applied to model competition between neighbors of a closely related sagebrush species (Adler et al., 2010; Chu and Adler, 2015).

To estimate the strength and spatial scale of crowding effect, we used inverse modeling to capture neighbor interactions (Adler et al., 2010; Canham and Uriarte, 2006; Ribbens et al., 1994), with the relative growth rate at time $t$ as a response, and plant size and crowding index at time $t-1$ as predictors. We modeled growth as a normallydistributed random variable using the following structure:

$$
\begin{aligned}
& g_{\mathrm{t}, \mathrm{s}} \sim \operatorname{Normal}\left(\mu_{i, s, t}, \sigma^{2}\right) \\
& \mu_{i, s, t}=\alpha_{[s]}+\beta_{[s]} \operatorname{Size}_{i, \mathrm{t}-1}+\gamma_{[s]} \mathrm{W}_{t-1}
\end{aligned}
$$

where $g_{t}$ is growth at time $t, \alpha_{[s]}$ is the average relative growth rate of subspecies:cytotype group $s, S_{i z} e_{i}$ is the crown volume of the target plant at $t-1, \gamma_{[s]}$ determines the strength and the mode of competitive effect on plant $i$ by neighbors $j$, at time $t$ - 1 . All three unknown parameters were modeled as random effects by subspecies:cytotype group identity $[s]$.

The survival models had a similar structure and predictors, and were modeled using a Bernoulli distribution:

$$
\begin{aligned}
& s_{\mathrm{t}} \sim \operatorname{Bernoulli}\left(\theta_{i, s, t}\right) \\
& \operatorname{logit}\left(\theta_{i, s, t}\right)=\alpha_{[s]}+\beta_{[s]} \operatorname{Size}_{i, \mathrm{t}-1}+\gamma_{[s]} W_{t-1}
\end{aligned}
$$

Our hierarchical model structure enabled us to fit models that relate to our three hypotheses. To test the first hypothesis, that plant-plant interactions vary between 
subspecies and ploidy level, we quantified how the crowding parameter $(\gamma)$ varied between subspecies:cytotype groups across all models. Positive values of $\gamma$ indicate facilitation, while negative values of $\gamma$ indicate competition. To test the second hypothesis, we quantified differences in neighborhood interaction parameters between our three sites which reflect the change in crowding along an environmental gradient. We expected neutral or positive interactions under harsher conditions, and a shift in a negative direction as conditions improve. To test the third hypothesis, we quantified differences in neighborhood interactions between the early and late census intervals. We expected that crowding effect in early stage of stand development will be weaker and intensify over time.

We fit hierarchical Bayesian models using the Hamiltonian Monte Carlo algorithm from 'rstan' package in R (Stan Development Team 2018, R Core Team 2018). We obtained samples from the posterior distribution for each census interval by running 4 chains, 10000 iterations each, with a warm-up period of 9500 iterations. To evaluate model convergence, we visually assessed the behavior and mixing of chains and checked that 'Rhat' values were below the threshold of 1.1 (Gelman and Rubin, 1992), and checked each model for divergent transitions. For posterior sampling, we chose weakly informed, normally distributed priors centered at zero, with the variance that captured biologically meaningful effect sizes. All predictors were standardized by centering them around the mean and dividing by two standard deviations (Gelman and Hill, 2006). We evaluated the fit of our spatial models by calculating WAIC scores (Hooten and Hobbs, 2015) and comparing the fit models, that only included an individual's size and subspecies:cytotype identity as predictor terms to models that included the neighborhood 
term $\left(\gamma_{[s]} W\right)$ intrinsic demographic parameters only reflecting performance in isolation, with those that had an additional non-linear crowding term.

\section{Results}

After the first growing season and the first winter, the sample size in Orchard was reduced to 419 for the first census interval, and over the course of the experiment down to 255 individuals. In Majors Flat, 448 individuals were present during the second growing season and the sample size was reduced to 368 by 2018 . Our data set from the Ephraim garden includes only the second growing season when 434 plants were alive after the first winter.

On the monthly scale, the community level growth in isolation of sagebrush plants in Orchard common garden in 2011 and 2018 was at $0.0038 \mathrm{~m}^{3} \mathrm{month}^{-1}$ (95\%CI: $0.0019,0.0057)$ and 0.0224 (95\%CI: $-0.0038,0.0421)$ respectively (Fig. S1). Growth rates were initially higher in Majors Flat common garden, with the median values of $0.0214 \mathrm{~m}^{3}$ month $^{-1}$ (95\%CI: 0.0104, 0.0383) in 2011 and $0.0114 \mathrm{~m}^{3} \mathrm{month}^{-1}$ (95\%CI: 0.0199, 0.033) in 2018. In Ephraim, the median growth rate was estimated at 0.021 $\mathrm{m}^{3}$ month $^{-1}$ (95\%CI: 0.0197, 0.0221). On the subspecies level, A.t. tridentata had higher growth rates compared to other subspecies in two sites (Fig. S2). This difference, however, was present during the 2011 census interval and did not seem to persist until 2018 in either location. In particular, A.t. tridentata: $2 x$ had higher growth rate during 2011 in Orchard at $0.0062 \mathrm{~m}^{3} \mathrm{month}^{-1}$ compared to the community level medians. A similar pattern was also observed in Majors Flat, where both cytotypes of A.t. tridentata had higher growth rates in isolation than either A.t. vaseyana or A.t. wyomingensis. For Ephraim 2011, Orchard and Majors Flat 2018 census intervals, the differences in the 
average growth rate among subspecies:cytotype groups were minimal with overlapping posterior distributions (Fig. S2).

The estimates for survival in isolation also differed considerably. In Orchard, the median community-level survival was $56 \%$ (95\%CI: $28.4,79.4$ ), versus $79.8 \%$ in Majors Flat (95\%CI: 52.3, 90.8). The median probability of survival in Orchard was lowest for A.t. vaseyana:2x at $22.4 \%$, and highest for A.t. tridentata: $4 \mathrm{x}$ at $88.5 \%$ (Fig. S3). In Majors Flat, the survival in isolation was generally higher and followed the same pattern by subspecies:cytotype group.

The estimated interaction coefficients varied between the subspecies:cytotype groups, the three common garden locations, as well as development stage (Fig. 1). The parameter values indicate the change to target plant growth or probability of survival in isolation when the crowding index is increased by two SD. With respect to our first hypothesis, subspecies:cytotype differences in response to crowding, the median crowding effects for A.t. tridentata:2x and, to a lesser degree A.t. tridentata:4x, were stronger (more negative) when compared to the common garden average effects (Fig. 3). This general pattern persisted across common gardens and census intervals. In terms of survival, crowding had a positive effect on A.t. vaseyana:4x, which was only observed in Majors Flat (Fig. 4).

As expected under our second hypothesis, plant-plant interactions were more important for growth in Majors Flat and Ephraim, the sites with higher precipitation and cooler temperatures. Thus, during the 2011 census interval in Orchard (driest site) most of the intraspecific neighbor interactions had negligible impact on growth, with the mean community level probability of negative effect of $69.9 \%$. In contrast, in Majors Flat and 
Ephraim gardens this probability was higher with respect to the overall averages as well as by subspecies, but the effect size varied. The probability of negative neighbor effects on A.t. tridentata:2x in both of the Utah gardens was $>95 \%$ (Fig. 3). The median effect on growth in isolation for A.t. tridentata: $2 \mathrm{x}$ was -0.01 and $-0.003 \mathrm{~m}^{3} \mathrm{month}^{-1}$ in Majors Flat 2011 and Ephraim respectively. A.t. wyomingensis showed intermediate response with a posterior mean of -0.005 and $-0.0008 \mathrm{~m}^{3} \mathrm{months}^{-1}$ and a probability of negative interactions $90.7 \%$ and $71.3 \%$ for Majors Flat 2011 and Ephraim gardens respectively. We also found evidence for positive crowding effect on survival in one of the gardens (Fig. 4). In Majors Flat, the two cytotypes of A.t. vaseyana and A.t. tridentata:4x were more likely to benefit from their neighbors, suggesting facilitative interactions. The probability of positive crowding effect for A.t. vaseyana:2x and A.t. vaseyana:4x was $92.6 \%$ and $97.3 \%$ respectively, and $86.7 \%$ for A.t. tridentata:4x. The effect on survival for other subspecies:cytotype groups was indiscernible from zero.

We predicted that plant-plant interactions will intensify with time as the plants grew, but the observed change in effect size was variable. Over time, during 2018 growth season in Orchard the overall probability of negative crowding effect increased to $81.3 \%$ with the median effect size on growth $-0.0119 \mathrm{~m}^{3}$ month $^{-1}$ (95\%CI: $\left.-0.0449,0.0267\right)$. On the subspecies level, the coefficients for A.t. vaseyana and A.t. wyomingensis in Orchard were very close to zero, and A.t. tridentata: $2 \mathrm{x}$ had the highest probability of negative interactions with neighbors $(94.9 \%)$ with a posterior median of $-0.0202 \mathrm{~m}^{3} \mathrm{month}^{-1}$ (Fig. 2). The distinct effects of crowding observed in Majors Flat common garden in 2011 were no longer evident in 2018 (Fig. S4). 
The scaling parameter associated with the rate of decline in neighbor effect indicates the spatial extent at which neighbors can affect the target plant. We modeled this parameter as a fixed effect and the coefficients were fairly consistent across time and space. The estimated values for this parameter suggest that the effect of neighbors becomes negligible beyond a distance of two meters from the target plant (Fig. 5). We also did not find any difference between the estimates of parameter $c$, which indicates the contribution of each subspecies:cytotype group to the cumulative crowding term, suggesting that the response was independent from the identity of the neighbor.

\section{Discussion}

Using a long-term experimental dataset, we applied spatially-explicit neighborhood models to evaluate how intraspecific variation alters plant-plant interactions. This approach allowed us to account for plant intraspecific identity, size, and the distance between neighbors to quantify plant-plant interactions. Our results suggest that distinct subspecies and cytotypes may have different capacity for neighbor tolerance reflected in growth and survival vital rates. These differences appear to be subject to environmental conditions and change over time which is generally consistent with the framework of the stress-gradient hypothesis (SGH) and individual ontogenic stages of plant development (He et al., 2013; Maestre et al., 2009; Miriti, 2006). Specifically, the differences by location appear to be more pronounced compared to the effects of time in nine years of stand development. Our study complements currently scarce experimental evidence on the spatial and temporal variability of plant-plant interactions on intraspecific level including cytotypes and subspecies of $A$. tridentata, a keystone species of the arid Great Basin ecosystems. 
Species coexistence and plant-plant interactions have been intensively investigated (Adler et al., 2018), it is unclear if divergent ecological traits within $A$. tridentata can result in differential patterns of interaction between subspecies and cytotypes. The overarching trend in our results on the subspecies:cytotype level suggests that growth rates of A.t. tridentata:2x, and to a lesser degree A.t. tridentata:4x are more prone to be affected by negative crowding effect. Previous findings are indirectly comparable with our results where A.t. tridentata, among the three subspecies, was associated with a colonial type of life strategy (Bonham et al., 1991). This strategy is characterized by a relatively high growth rate while limited competitive capacity, which to some degree matches our results. In agreement with the general ecological theory (Chapin et al., 1993; Tilman, 1990), both cytotypes of A.t. tridentata which showed higher growth in isolation compared to the common garden average were also more sensitive to competition in growth. This type of competition effect could underlie a stabilizing effect on size distribution within population indicating that individuals with conservative growth strategies may not be in disadvantage to fast growing neighbors (Schwinning, 1996; Schwinning and Weiner, 1998).

In addition, we found evidence that polyploidy in A. tridentata could also have an effect on intraspecific plant-plant interactions. Specifically, A.t. tridentata: $4 \mathrm{x}$ had higher neighbor tolerance compared to its diploid variant when the effect on the latter was observable. In agreement with other studies (Hahn et al., 2012; Maceira et al., 1993; Schlaepfer et al., 2010), polyploids generally have higher competitive capacity as young recruits are likely to face competition from established populations of diploid plants (Rodriguez, 1996) or extensive loss of fertility (Kramer et al., 2018). Accounting for 
neighbor interactions in space explicitly will provide insights into evolutionary origins and mechanisms of polyploidy in plant species.

Environmental conditions, distinct in all three locations (Chaney et al., 2017), proved to be important for intraspecific biotic interactions in growth and survival. Our results support the idea of stronger competitive interactions under more favorable conditions (Bertness and Callaway, 1994; Brooker and Callaghan, 1998), and suggest that intraspecific identity may alter the response to stress and neighbor impacts. We found evidence that generally corroborates the pattern expected under the SGH in our growth models although the magnitude of interaction effect differed among subspecies and cytotypes. In addition to differences among sites, the results also indicate a temporal pattern associated with growth variation. For growth, during the early development stage, the overall crowding effect in the driest common garden was close to zero and shifted in the negative direction during the same time in the other two gardens where precipitation was higher (Table 1). This pattern suggests that the onset of competition may have been delayed in the driest site, compared to the sites that promote higher growth rates initially, reinforcing the link between growth and competitive interactions (Callaway et al., 2003). Among five analyzed subspecies:cytotype groups, A.t. tridentata:2x appeared to be most responsive to environmental gradient in terms of growth, and A.t. vasyana:4x in terms of survival. The absence of crowding impact on growth could indicate that plants are reaching their maximum potential size (Evans et al., 1991; Miglia et al., 2005), and negative interactions between neighbors could be manifested through other demographic rates such as reproduction (B. Richardson unpublished data). 
The crowding effect on survival in the driest site was indiscernible from zero and the median shifted in a positive direction with higher precipitation and lower minimum temperatures. Again, intraspecific identity mattered in this response as well, where generally more conservative in growth A.t. vaseyana was associated with positive crowding effect from nearby individuals. This mechanism could potentially include protection from cool temperatures documented to be detrimental for survival of $A$. tridentata (Brabec et al., 2017; Loik and Redar, 2003), or associational resistance to herbivory where subspecies with lower palatability might protect those that are more palatable or smaller in stature (Barbosa et al., 2009; Rosentreter, 2004; Shiojiri and Karban, 2008). Although the observed patterns in growth and survival models may involve different mechanisms of interactions, the results generally corroborate SGH in the common garden system. This variation, however, was not uniform across subspecies:cytotype groups and vital rates benefiting smaller stature A.t. vaseyana in wetter and cooler sites in terms of survival, while A.t. tridentata appear to be most neighbor intolerant in terms of growth. Comparing the crowding effects across census intervals and sites, the differences were more apparent between different locations and less so in time corresponding different stages of stand development. Overall, our study suggests that plant-plant interactions on the level of subspecies and cytotype are subject to environmental and temporal effect expected under SGH, however, the specific response could also depend on the intraspecific identity of the target plant.

This study was conducted using a dataset from a long term common garden experiment which included a generally practiced spatial design where neighbors are incrementally equidistant to a target plant. This spatial attribute as well as the genotypic 
diversity of 55 source populations in the common garden represent experimental conditions that are unlikely to occur in natural ecosystems. However, a mixing of plant material from genetically distant populations in restoration treatments is common (Germino et al., 2018). For large-scale restoration projects, the scope of an intervention and limitations in local plant material requires sourcing seeds from various locations, and distinct subspecies, and cytotypes. Therefore, instances where such interventions have been implemented represent existing study cases where diverse population coexist, while future restoration treatments could serve as potential natural experiments for studying how population dynamics depend on intraspecific diversity (Gellie et al., 2018).

In this study, we show that the effect of conspecific plant-plant interactions varied from competition to facilitation for distinct subspecies and cytotypes. These interactions were variable in space and time and depended on the population vital rate considered. Additionally, we found the absolute differences in effect size were more apparent for growth and less so for survival of the studied species (Caughlin et al., 2019). We show how variation in conspecific interactions could alter the immediate population viability, which could also provide mechanistic insights into evolutionary processes related to population coexistence and polyploidy. The understanding of spatial interactions on the level of individual plants allows to explicitly account for space and plant identity when modeling the establishment process of autopolyploids. The implications of the presented results also include the potential to include spatial designs into restoration interventions (McCallum et al., 2018) and to account for spatial interactions when designing or monitoring long-term experiments such as common garden trials. 


\section{REFERENCES}

Adams, T.P., Holland, E.P., Law, R., Plank, M.J., Raghib, M., 2013. On the growth of locally interacting plants: differential equations for the dynamics of spatial moments. Ecology 94, 2732-2743.

Adler, P.B., Ellner, S.P., Levine, J.M., 2010. Coexistence of perennial plants: an embarrassment of niches. Ecology Letters 13, 1019-1029.

Adler, P.B., Smull, D., Beard, K.H., Choi, R.T., Furniss, T., Kulmatiski, A., Meiners, J.M., Tredennick, A.T., Veblen, K.E., 2018. Competition and coexistence in plant communities: intraspecific competition is stronger than interspecific competition. Ecology Letters 21, 1319-1329.

Barabás, G., D’Andrea, R., Stump, S.M., 2018. Chesson’s coexistence theory. Ecological Monographs 88, 277-303.

Barbosa, P., Hines, J., Kaplan, I., Martinson, H., Szczepaniec, A., Szendrei, Z., 2009. Associational Resistance and Associational Susceptibility: Having Right or Wrong Neighbors. Annual Review of Ecology, Evolution, and Systematics 40, 120.

Bennett, J.A., Riibak, K., Tamme, R., Lewis, R.J., Pärtel, M., 2016. The reciprocal relationship between competition and intraspecific trait variation. J Ecol 104, $1410-1420$.

Bertness, M.D., Callaway, R., 1994. Positive interactions in communities. Trends in Ecology \& Evolution 9, 191-193.

Bonham, C.D., Cottrell, T.R., Mitchell, J.E., 1991. Inferences for life history strategies of Artemisia tridentata subspecies. Journal of Vegetation Science 2, 339-344. 
Brabec, M.M., Germino, M.J., Richardson, B.A., 2017. Climate adaption and post-fire restoration of a foundational perennial in cold desert: insights from intraspecific variation in response to weather. J Appl Ecol 54, 293-302.

Brooker, R.W., Callaghan, T.V., 1998. The Balance between Positive and Negative Plant Interactions and Its Relationship to Environmental Gradients: A Model. Oikos 81, 196-207.

Calama, R., Conde, M., de-Dios-García, J., Madrigal, G., Vázquez-Piqué, J., Gordo, F.J., Pardos, M., 2019. Linking climate, annual growth and competition in a Mediterranean forest: Pinus pinea in the Spanish Northern Plateau. Agricultural and Forest Meteorology 264, 309-321.

Callaway, R.M., Pennings, S.C., Richards, C.L., 2003. Phenotypic Plasticity and Interactions Among Plants. Ecology 84, 1115-1128.

Canham, C.D., Uriarte, M., 2006. Analysis Of Neighborhood Dynamics Of Forest Ecosystems Using Likelihood Methods And Modeling. Ecological Applications $16,62-73$.

Caughlin, T.T., Ferguson, J.M., Lichstein, J.W., Zuidema, P.A., Bunyavejchewin, S., Levey, D.J., 2015. Loss of animal seed dispersal increases extinction risk in a tropical tree species due to pervasive negative density dependence across life stages. Proc Biol Sci 282.

Caughlin, T.T., Peña-Domene, M. de la, Martínez-Garza, C., 2019. Demographic costs and benefits of natural regeneration during tropical forest restoration. Ecology Letters 22, 34-44.

Čertner, M., Sudová, R., Weiser, M., Suda, J., Kolář, F., 2019. Ploidy-altered phenotype interacts with local environment and may enhance polyploid establishment in Knautia serpentinicola (Caprifoliaceae). New Phytologist 221, 1117-1127.

Chaney, L., Richardson, B.A., Germino, M.J., 2017. Climate drives adaptive genetic responses associated with survival in big sagebrush (Artemisia tridentata). Evol Appl 10, 313-322. 
Chapin, F.S., Autumn, K., Pugnaire, F., 1993. Evolution of Suites of Traits in Response to Environmental Stress. The American Naturalist 142, S78-S92.

Chesson, P., 2000. Mechanisms of Maintenance of Species Diversity. Annu. Rev. Ecol. Syst. 31, 343-366.

Chesson, P., 2018. Updates on mechanisms of maintenance of species diversity. Journal of Ecology 106, 1773-1794.

Chu, C., Adler, P.B., 2015. Large niche differences emerge at the recruitment stage to stabilize grassland coexistence. Ecological Monographs 85, 373-392.

Currie, D.J., Mittelbach, G.G., Cornell, H.V., Field, R., Guégan, J.-F., Hawkins, B.A., Kaufman, D.M., Kerr, J.T., Oberdorff, T., O’Brien, E., Turner, J.R.G., 2004. Predictions and tests of climate-based hypotheses of broad-scale variation in taxonomic richness. Ecology Letters 7, 1121-1134.

Davis, M.B., Shaw, R.G., 2001. Range Shifts and Adaptive Responses to Quaternary Climate Change. Science 292, 673-679.

DeMalach, N., Zaady, E., Weiner, J., Kadmon, R., 2016. Size asymmetry of resource competition and the structure of plant communities. Journal of Ecology 104, 899910.

Evans, R.D., Black, R.A., 1993. Growth, Photosynthesis, and Resource Investment for Vegetative and Reproductive Modules of Artemisia Tridentata. Ecology 74, $1516-1528$.

Evans, R.D., Black, R.A., Link, S.O., 1991. Reproductive Growth During Drought in Artemisia tridentata Nutt. Functional Ecology 5, 676-683.

Gellie, N.J., Breed, M.F., Mortimer, P.E., Harrison, R.D., Xu, J., Lowe, A.J., 2018. Networked and embedded scientific experiments will improve restoration outcomes. Frontiers in Ecology and the Environment 16, 288-294.

Gelman, A., Hill, J., 2006. Data Analysis Using Regression and Multilevel/Hierarchical Models. Cambridge University Press. 
Gelman, A., Rubin, D.B., 1992. Inference from Iterative Simulation Using Multiple Sequences. Statistical Science 7, 457-472.

Germino, M.J., Moser, A.M., Sands, A.R., 2018. Adaptive variation, including local adaptation, requires decades to become evident in common gardens. Ecological Applications.

Groot, G.A. de, Zuidema, P.A., Groot, H. de, During, H.J., 2012. Variation in ploidy level and phenology can result in large and unexpected differences in demography and climatic sensitivity between closely related ferns. American Journal of Botany 99, 1375-1387.

Hahn, M.A., Buckley, Y.M., Müller-Schärer, H., 2012. Increased population growth rate in invasive polyploid Centaurea stoebe in a common garden. Ecology Letters 15, 947-954.

Hart, S.P., Schreiber, S.J., Levine, J.M., 2016. How variation between individuals affects species coexistence. Ecology Letters 19, 825-838.

Havens, K., Vitt, P., Still, S., Kramer, A.T., Fant, J.B., Schatz, K., 2015. Seed Sourcing for Restoration in an Era of Climate Change. Natural Areas Journal 35, 122-133.

He, Q., Bertness, M.D., Altieri, A.H., 2013. Global shifts towards positive species interactions with increasing environmental stress. Ecology Letters 16, 695-706.

Hooten, M.B., Hobbs, N.T., 2015. A guide to Bayesian model selection for ecologists. Ecological Monographs 85, 3-28.

Humphrey, L.D., Pyke, D.A., 1998. Demographic and growth responses of a guerrilla and a phalanx perennial grass in competitive mixtures. Journal of Ecology 86, 854-865.

Kramer, A.T., Wood, T.E., Frischie, S., Havens, K., 2018. Considering ploidy when producing and using mixed-source native plant materials for restoration: Ploidy in mixed-source native plant materials. Restoration Ecology 26, 13-19.

Law, R., Murrell, D.J., Dieckmann, U., 2003. Population Growth in Space and Time: Spatial Logistic Equations. Ecology 84, 252-262. 
Leger, E.A., 2008. THE ADAPTIVE VALUE OF REMNANT NATIVE PLANTS IN INVADED COMMUNITIES: AN EXAMPLE FROM THE GREAT BASIN. Ecological Applications 18, 1226-1235.

Li, B.-H., Xu, X.-M., Ridout, M.S., 2004. Modelling the establishment and spread of autotetraploid plants in a spatially heterogeneous environment. Journal of Evolutionary Biology 17, 562-573.

Lind, B.M., Friedline, C.J., Wegrzyn, J.L., Maloney, P.E., Vogler, D.R., Neale, D.B., Eckert, A.J., 2017. Water availability drives signatures of local adaptation in whitebark pine (Pinus albicaulis Engelm.) across fine spatial scales of the Lake Tahoe Basin, USA. Molecular Ecology 26, 3168-3185.

Loik, M.E., Redar, S.P., 2003. Microclimate, freezing tolerance, and cold acclimation along an elevation gradient for seedlings of the Great Basin Desert shrub, Artemisia tridentata. Journal of Arid Environments 54, 769-782.

Maceira, N.O., Jacquard, P., Lumaret, R., 1993. Competition between diploid and derivative autotetraploid Dactylis glomerata L. from Galicia. Implications for the establishment of novel polyploid populations. New Phytologist 124, 321-328.

Maestre, F.T., Callaway, R.M., Valladares, F., Lortie, C.J., 2009. Refining the stressgradient hypothesis for competition and facilitation in plant communities. Journal of Ecology 97, 199-205.

Mahalovich, M.F., McArthur, E.D., 2005. Sagebrush (Artemisia spp.) Seed and Plant Transfer Guidelines. Native Plants Journal 5, 141-148.

McArthur, E.D., Pope, C.L., Freeman, D.C., 1981. Chromosomal Studies of Subgenus Tridentatae of Artemisia: Evidence for Autopolyploidy. American Journal of Botany 68, 589-605.

McCallum, K.P., Lowe, A.J., Breed, M.F., Paton, D.C., 2018. Spatially designed revegetation - why the spatial arrangement of plants should be as important to revegetation as they are to natural systems. Restoration Ecology 26, 446-455.

Miglia, K.J., Mcarthur, E.D., Moore, W.S., Wang, H., Graham, J.H., Freeman, D.C., 2005. Nine-year reciprocal transplant experiment in the gardens of the basin and 
mountain big sagebrush (Artemisia tridentata: Asteraceae) hybrid zone of Salt Creek Canyon: the importance of multiple-year tracking of fitness. Biological Journal of the Linnean Society 86, 213-225.

Miriti, M.N., 2006. Ontogenetic shift from facilitation to competition in a desert shrub. Journal of Ecology 94, 973-979.

Moya-Larano, J., 2010. Can Temperature and Water Availability Contribute to the Maintenance of Latitudinal Diversity by Increasing the Rate of Biotic Interactions? The Open Ecology Journal 3, 1-13.

Münzbergová, Z., Haisel, D., 2018. Effects of polyploidization on the contents of photosynthetic pigments are largely population-specific. Photosynthesis Research.

Petit, C., Bretagnolle, F., Felber, F., 1999. Evolutionary consequences of diploidpolyploid hybrid zones in wild species. Trends in Ecology \& Evolution 14, 306311.

Petrone Mendoza, S., Lascoux, M., Glémin, S., 2018. Competitive ability of Capsella species with different mating systems and ploidy levels. Ann Bot 121, 12571264.

R Core Team, 2018. R: A language and environment for statistical computing. R Foundation for Statistical Computing, Vienna, Austria. https://www.Rproject.org/.

Ribbens, E., Silander, J.A., Pacala, S.W., 1994. Seedling Recruitment in Forests: Calibrating Models to Predict Patterns of Tree Seedling Dispersion. Ecology 75, 1794-1806.

Richardson, B.A., Chaney, L., 2018. Climate-based seed transfer of a widespread shrub: population shifts, restoration strategies, and the trailing edge. Ecological Applications 28, 2165-2174.

Richardson, B.A., Page, J.T., Bajgain, P., Sanderson, S.C., Udall, J.A., 2012. Deep sequencing of amplicons reveals widespread intraspecific hybridization and multiple origins of polyploidy in big sagebrush (Artemisia tridentata; Asteraceae). Am. J. Bot. 99, 1962-1975. 
Rieseberg, L.H., Willis, J.H., 2007. Plant Speciation. Science 317, 910-914.

Rodriguez, D.J., 1996. A Model for the Establishment of Polyploidy in Plants. The American Naturalist 147, 33-46.

Rosentreter, R., 2004. Sagebrush Identification, Ecology, and Palatability Relative to Sage-Grouse 14.

Schlaepfer, D.R., Edwards, P.J., Billeter, R., 2010. Why only tetraploid Solidago gigantea (Asteraceae) became invasive: a common garden comparison of ploidy levels. Oecologia 163, 661-673.

Schwinning, S., 1996. Decomposition Analysis of Competitive Symmetry and Size Structure Dynamics. Annals of Botany 77, 47-58.

Schwinning, S., Weiner, J., 1998. Mechanisms determining the degree of size asymmetry in competition among plants. Oecologia 113, 447-455.

Shao, X., Brown, C., Worthy, S.J., Liu, L., Cao, M., Li, Q., Lin, L., Swenson, N.G., 2018. Intra-specific relatedness, spatial clustering and reduced demographic performance in tropical rainforest trees. Ecology Letters 21, 1174-1181.

Shiojiri, K., Karban, R., 2008. Seasonality of herbivory and communication between individuals of sagebrush. Arthropod-Plant Interactions 2, 87-92.

Shryock, D.F., DeFalco, L.A., Esque, T.C., 2014. Life-history traits predict perennial species response to fire in a desert ecosystem. Ecol Evol 4, 3046-3059.

Shryock, D.F., Havrilla, C.A., DeFalco, L.A., Esque, T.C., Custer, N.A., Wood, T.E., 2015. Landscape genomics of Sphaeralcea ambigua in the Mojave Desert: a multivariate, spatially-explicit approach to guide ecological restoration. Conserv Genet 16, 1303-1317.

Shultz, L.M., 2009. Monograph of Artemisia Subgenus Tridentatae (AsteraceaeAnthemideae). Systematic Botany Monographs 89, 1-131.

Simard, S.W., Sachs, D.L., 2004. Assessment of interspecific competition using relative height and distance indices in an age sequence of seral interior cedar-hemlock forests in British Columbia. Canadian Journal of Forest Research 34, 1228-1240. 
Stan Development Team, 2018. RStan: the R interface to Stan. R package version 2.18.2. http://mc-stan.org/.

Sturges, D.L., 1977. Soil Water Withdrawal and Root Characteristics of Big Sagebrush. American Midland Naturalist 98, 257.

Tilman, D., 1990. Constraints and Tradeoffs: Toward a Predictive Theory of Competition and Succession. Oikos 58, 3-15.

Umaña, M.N., Zipkin, E.F., Zhang, C., Cao, M., Lin, L., Swenson, N.G., 2018. Individual-level trait variation and negative density dependence affect growth in tropical tree seedlings. Journal of Ecology 106, 2446-2455.

Uriarte, M., Menge, D., 2018. Variation between individuals fosters regional species coexistence. Ecology Letters 21, 1496-1504.

Werner, C.M., Vaughn, K.J., Stuble, K.L., Wolf, K., Young, T.P., 2016. Persistent asymmetrical priority effects in a California grassland restoration experiment. Ecol Appl 26, 1624-1632.

Wood, T.E., Takebayashi, N., Barker, M.S., Mayrose, I., Greenspoon, P.B., Rieseberg, L.H., 2009. The frequency of polyploid speciation in vascular plants. Proceedings of the National Academy of Sciences 106, 13875-13879.

Wright, A., Schnitzer, S.A., Reich, P.B., 2014. Living close to your neighbors: the importance of both competition and facilitation in plant communities. Ecology 95, 2213-2223.

Yastrebov, A.B., 1996. Different Types of Heterogeneity and Plant Competition in Monospecific Stands. Oikos 75, 89-97.

Zhao, H.-L., Zhou, R.-L., Su, Y.-Z., Zhang, H., Zhao, L.-Y., Drake, S., 2007. Shrub facilitation of desert land restoration in the Horqin Sand Land of Inner Mongolia. Ecological Engineering 31, 1-8. 


\section{Figures}

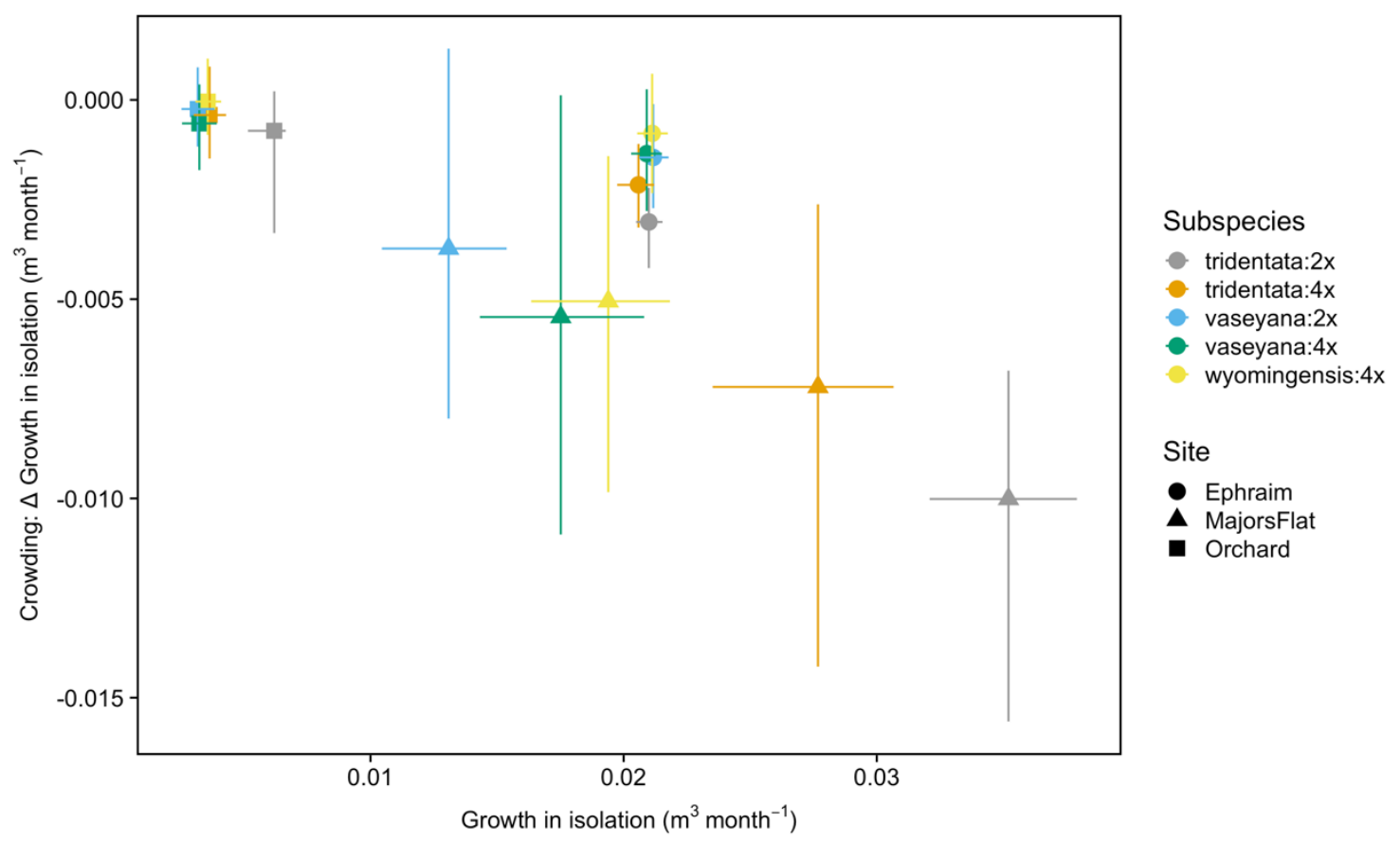

Figure 1: $\quad$ Posterior samples representing the relationship between the growth in isolation and crowding effect in three $A$. tridentata common gardens during the 2011 census interval. The $y$ axis represents the change to growth in isolation when the crowding effect is increased by $2 \mathrm{SD}$. The symbols show the medians of estimated parameters and the error bars indicate $68 \% \mathrm{CI}$. 


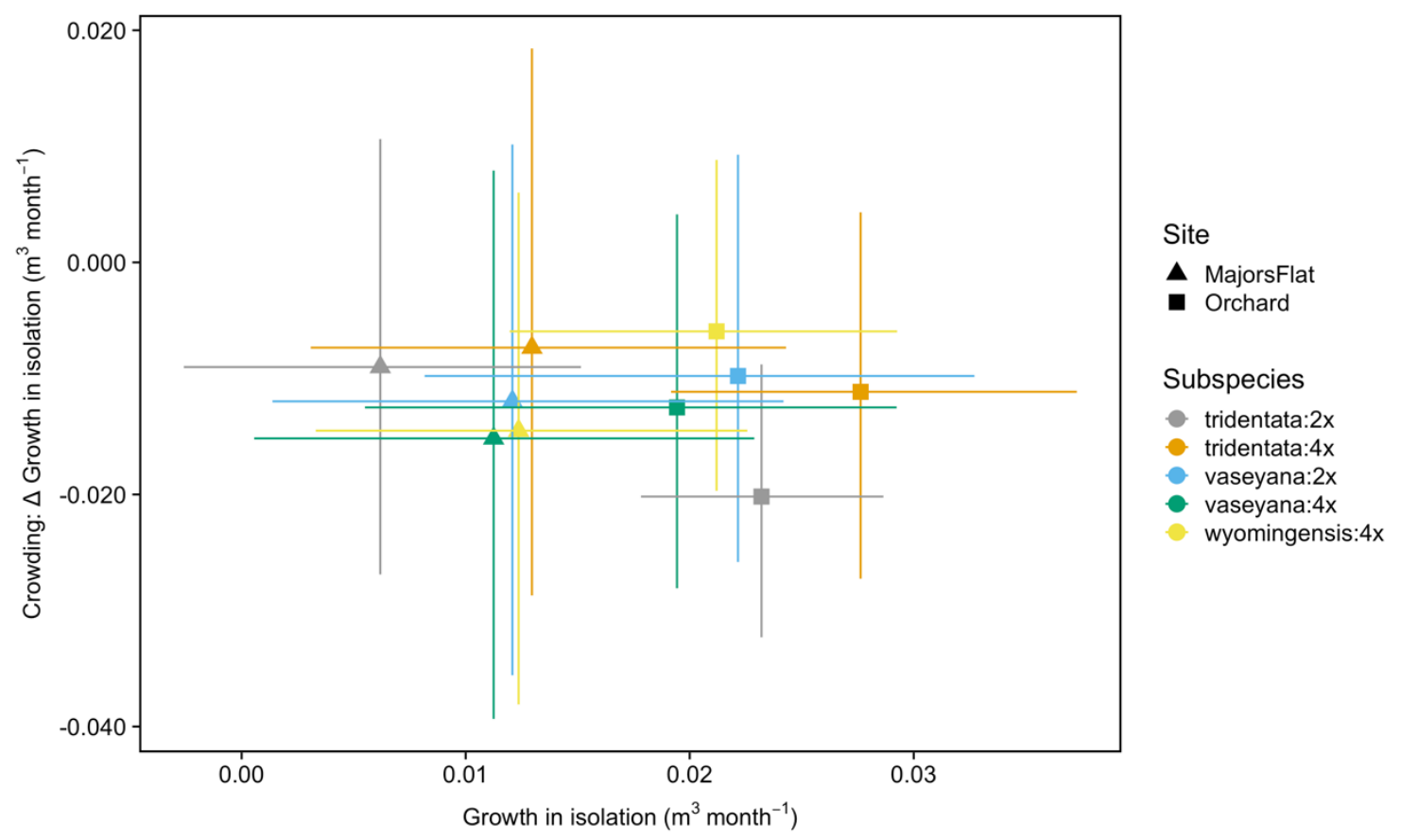

Figure 2: Posterior samples representing the relationship between the growth in isolation and crowding effect in two $A$. tridentata common gardens during the 2018 census interval. The $y$ axis represents the change to growth in isolation when the crowding effect is increased by 2 SD. The symbols show the medians of estimated parameters and the error bars indicate $68 \% \mathrm{CI}$. 


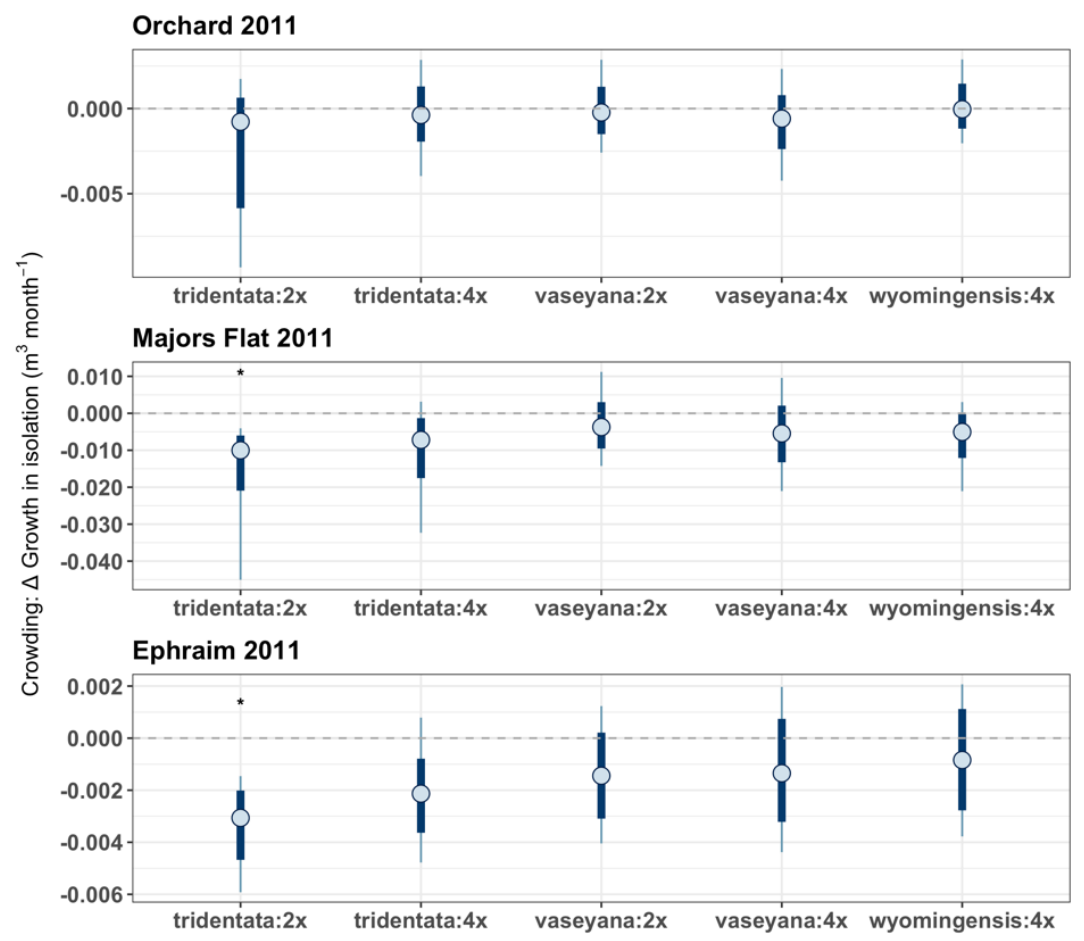

Figure 3: $\quad$ Posterior samples that represent the crowding effect on the relative growth rates (RGR) of $A$. tridentata in three common gardens using 2011 census interval. Thick lines represent $80 \%$ CI, while thinner lines indicate $95 \% \mathrm{CI}$. The $\mathrm{x}$ axis shows five subspecies:cytotype groups of $\boldsymbol{A}$. tridentata. The effect size corresponds to the change in RGR in isolation when crowding is increased by 2 SD. Values of zero indicate no crowding effect on RGR. 


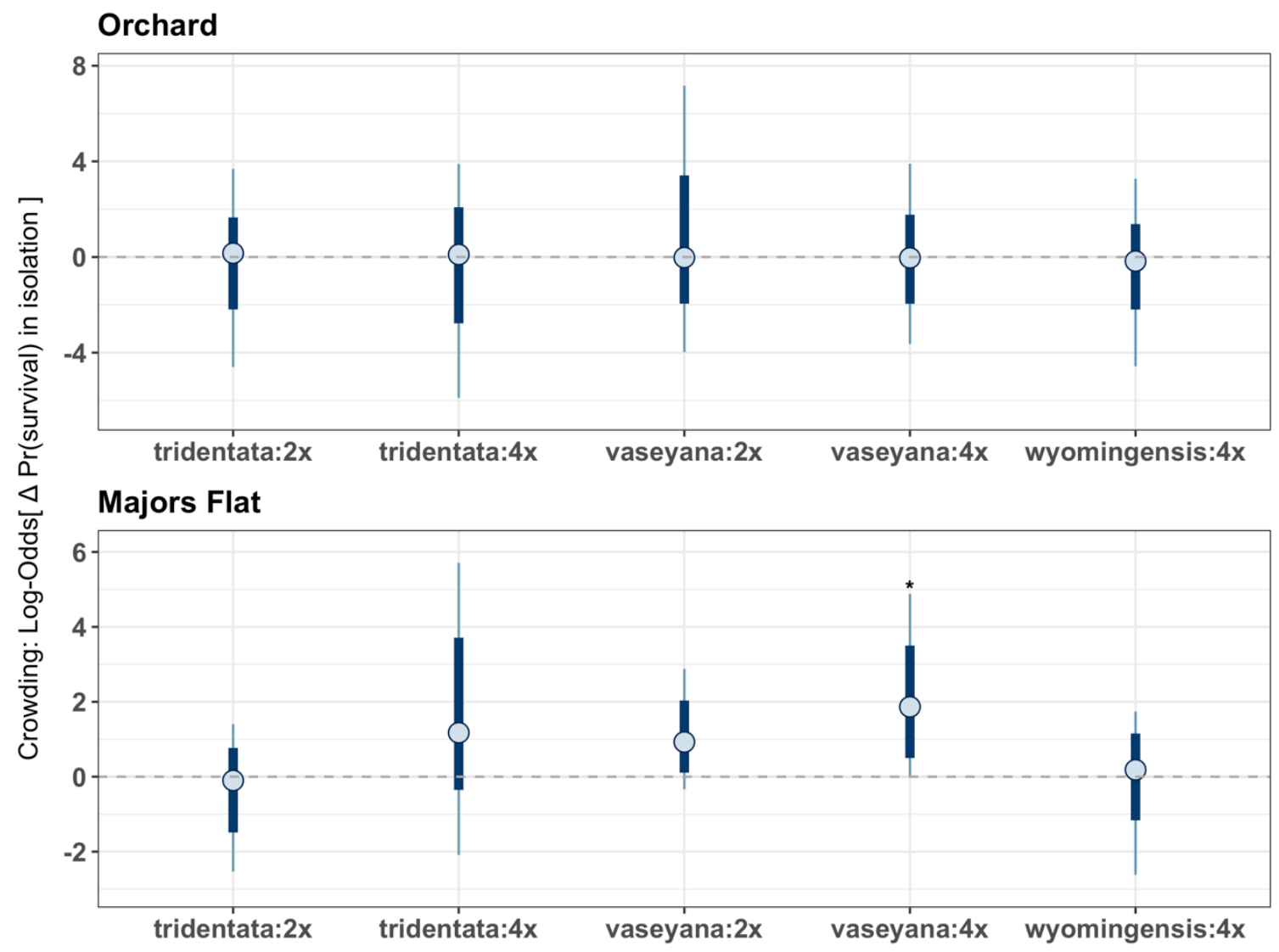

Figure 4: $\quad$ Posterior samples that represent the effect of crowding on survival probability in $A$. tridentata in two common gardens. The effect sizes are based on census interval between 2012 and 2018. Thick lines show $80 \% \mathrm{CI}$, while thinner lines indicate $95 \%$ CI. Coefficients indicate the change to survival in isolation when crowding is increased by $2 \mathrm{SD}$, and values of zero indicate no crowding effect. 


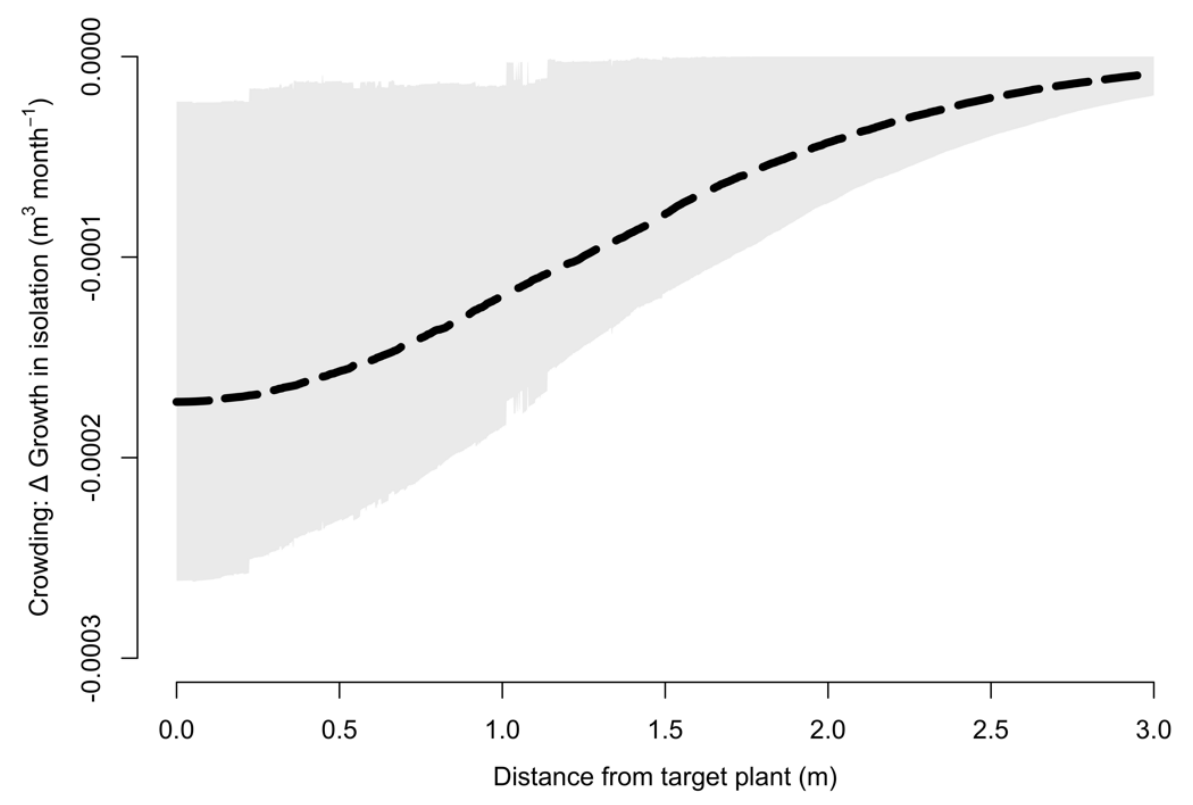

Figure 5: The rate of decline of crowding effect with distance in Majors Flat common garden during 2011 growth season for $A$.t. tridentata:2x. The black line corresponds to the median crowding effect, and the shaded area to the $1 \mathrm{SD}$. The $y$ axis represents growth in isolation decline of the target plant under the presence of an average neighbor. 


\section{Tables}

Table 1: Annual climate data for three common gardens during the experiment (2010-2017).

\begin{tabular}{|l|l|l|l|l|l|l|l|l|}
\hline Site & MAP & $\mathrm{SD}_{\text {map }}$ & $\mathrm{MAT}$ & $\mathrm{SD}_{\text {mat }}$ & $\mathrm{Tm}_{\min }$ & $\mathrm{SD}_{\text {tmin }}$ & $\mathrm{Tm}_{\max }$ & $\mathrm{SD}_{\text {tmax }}$ \\
\hline Orchard, ID & 307.519 & 91.029 & 10.838 & 0.715 & 3.538 & 0.958 & 18.113 & 0.690 \\
\hline Majors Flat, UT & 610.391 & 56.088 & 6.063 & 0.741 & -0.311 & 0.620 & 12.413 & 0.863 \\
\hline Ephraim, UT & 296.933 & 40.154 & 8.738 & 0.883 & 0.400 & 0.639 & 17.050 & 1.222 \\
\hline
\end{tabular}




\title{
CHAPTER TWO: QUANTIFYING INTRASPECIFIC VARIABILITY IN BIG SAGEBRUSH LATERAL ROOT EXTENT AND FUNCTIONING USING A DEUTERIUM TRACER EXPERIMENT
}

\begin{abstract}
Water availability in arid ecosystems is vital for plant community structure, dynamics, and ecosystem functioning. Despite a wide recognition that water is a major limiting resource for plant populations, we lack empirical evidence and understanding if and when water limitation can underlie resource competition. Experimental studies are necessary to elucidate plant-plant interactions in context of water limitation. We used a deuterium addition experiment to quantify belowground zone of influence in Artemisia tridentata, and tested if spatial neighborhood characteristics can alter plant water uptake. We introduced deuterium enriched water to plant interspaces in a long-term common garden experiment and measured deuterium composition of plant stems. We then applied non-linear, spatially-explicit models to test for differential water uptake and horizontal reach of A. tridentata, including three subspecies and two ploidy levels. The results suggest that water uptake from shallow horizons and root horizontal reach are related to intraspecific identity and ploidy level. Diploid cytotypes generally had smaller horizontal reach, and intraspecific differences were most noticeable between A.t. tridentata:4x and A.t. vaseyana:2x. We hypothesize that the observed differences in root growth allocation may result from a combination of ecotypic differences and physiological regulation including plant stress hormones. We also found that plant crown volume was a weak
\end{abstract}


predictor of water uptake in general, and that the effect of neighborhood crowding was indiscernible from zero, which likely suggests a symmetric partitioning of belowground water resources. Intraspecific variation in patterns of resource acquisition is particularly important in arid ecosystems in context of species coexistence, changing climate, and seasonal patterns of precipitation. Our study complements our understanding of big sagebrush lateral root structure and function, intraspecific variation in life strategies, and mechanisms of stress response.

\section{Introduction}

The spatial organization of belowground plant parts in plant communities impact multiple processes, from individual fitness to ecosystem function. Belowground interactions between neighboring plants could be one mechanism leading to biodiversitymaintaining niche differences (Chesson et al., 2004; Schenk, 2006). By affecting plant community species composition, spatial distribution and root interactions could impact critical ecosystem functions including nutrient cycling and primary production (Tilman et al., 1997). Furthermore, belowground processes are subject to global changes in biodiversity patterns including increasing rates of natural and assisted migration, biological invasions, and climate change (Chapin III et al., 2000; Germino et al., 2016; Havens et al., 2015). In arid environments, global changes are likely to have particularly strong impacts on belowground ecological processes as altered precipitation regimes impact the partitioning of scarce resources (Chesson et al., 2004; Fowler, 1986). Altogether, there is an urgent need to quantify spatial niche partitioning along the hydrological and nutrient gradients for plants in arid environments. 
Belowground competition and root interactions are likely to play a major role in species and community dynamics in sagebrush steppe ecosystems (Rau et al., 2011). There is evidence for strong plant-plant interactions between congeneric sagebrush plants and heterospecific neighbors, with implications for long-term species coexistence (Adler et al., 2010). Despite a common understanding that water availability is an important covariate in plant performance, explicitly linking water limitation to neighbor competition is difficult (Casper and Jackson, 1997; Loik et al., 2004). For big sagebrush, some experimental evidence favors the Walter's two-layered hypothesis (Flanagan and Ehleringer, 1991; Germino and Reinhardt, 2014), which should minimize water-based competition. Other studies have documented negative density dependence in arid ecosystems (Adler et al., 2010; Miriti et al., 2001), which likely results from belowground processes, as competition for light is rare due to generally sparse canopy cover. Nevertheless, we lack experimental studies that examine size-structured competitive interactions, and there is conflicting evidence for water competition in general (DiCristina and Germino, 2006; Goldberg and Novoplansky, 1997; Schenk and Mahall, 2002).

Big sagebrush, Artemisia tridentata, is one of the dominant shrub species of the arid western United States. Significant intraspecific variation related to a wide geographical distribution and high genetic diversity is another key feature of big sagebrush populations (Richardson and Chaney, 2018). Ecological theory proposes that, for stable coexistence, competitive interactions within species must be stronger compared to those between different species (Adler et al., 2010; Chesson, 2018), however, intraspecific variation directed to niche segregation could alleviate this effect (Hart et al., 
2016; Uriarte and Menge, 2018). This variation in ecophysiological characteristics between genetically different populations has consequences for long-term ecoevolutionary dynamics of sagebrush populations (Miglia et al., 2007; Richardson et al., 2012), and practical importance for post-fire restoration, where choosing locally-adapted sagebrush seeds promotes establishment success in heterogeneous landscapes (Germino et al., 2018). However, how intraspecific variation in local adaptation impacts belowground processes in big sagebrush subpopulations remains largely unknown.

In addition to ecophysiological plasticity, A. tridentata is a species with frequent polyploidy and complex phylogeny. Polyploidy in big sagebrush is a widespread process driven by local, landscape, and regional factors (Richardson et al., 2012). Intraspecific variability in cytotype level, the number of homologous chromosomes in a plant cell, can alter population vital rates (Groot et al., 2012) as well as plant competitive ability (Petrone Mendoza et al., 2018). For example, in arid environments where water availability is a primary driver of plant community structure, differences in water-use efficiency and drought tolerance between diploid and hybrid polyploid populations can alter their competitive ability (Leger, 2008; Maherali et al., 2009; Schwinning and Kelly, 2013). Multiple studies suggest higher drought tolerance in polyploids (Li et al., 1996; Van Laere et al., 2011) which could result in competitive advantages for polyploids under water-stressed conditions. Under these conditions, a distinct response in root growth to drought between diploid and polyploid populations may result in spatially-segregated hydrological niches (Araya et al., 2011; Xiong et al., 2006). Understanding how biotic factors such as plant-plant interactions interact with local abiotic conditions could explain how intraspecific variability promotes coexistence and development of genetically- 
diverse populations. Over its range, A. tridentata occupies habitats with distinct characteristics, including differences in soil profile depth. These differences underlie intraspecific patterns of big sagebrush distribution, and are associated with morphological and physiological traits related to plant water and nutrient use (Kolb and Sperry, 1999; Shultz, 2009). Local adaptations, including adaptations to soil profile depth, are likely to have a profound impact on root formation and functioning. For example, the ability of $A$. tridentata to utilize water resources from deep and shallow soils combined with variation in intraspecific stress tolerance may lead to different water acquisition patterns among the subspecies (Donovan and Ehleringer, 1994; Kolb and Sperry, 1999). Differences in water use from shallow soils and the ability of $A$. tridentata to maintain functional lateral roots through the dry season may be important for plant water status, photosynthesis, and seed production (Evans et al., 1991; Leffler et al., 2004; Loik, 2007). Therefore, the spatial scale of functionally-active lateral roots in shallow soils may be indicative of the differences in local adaptations and life-history strategies among the subspecies of $A$. tridentata. In addition, while multiple studies have addressed plant-water relationships and plant-plant interactions, fewer have assessed if water could underlie the mechanism of competitive interactions in arid ecosystems (but see Belcher et al., 1995; DiCristina and Germino, 2006; Kadmon, 1995; Schenk and Mahall, 2002). Consumptive competition, competition for the same resource, is a mechanism that can explain negative interactions between neighboring individuals (Goldberg, 1990). Investigating belowground resource competition is difficult due to the high plasticity and variability of root systems and logistical complexity of measuring them. Therefore, experimental studies are necessary to: (i) elucidate belowground root structure and functioning, and (ii) 
test if neighboring plants share common consumptive resources, such as water, and whether competition for these resources can underlie competitive interactions between neighboring big sagebrush individuals.

We conducted a deuterium oxide tracer experiment in an eight-year old $A$. tridentata common garden experimental plot to test if water in shallow soil horizons can be shared between neighboring individuals. We applied spatially-explicit models to characterize the neighborhood effect via belowground zone of influence (Casper et al., 2003), and to quantify the effect of neighboring individuals on tracer uptake by a target plant (i.e., crowding effect). We further ask if intraspecific variability on the level of subspecies:cytotype can underlie root architecture differences and competitive capacity realized through tracer uptake. Specific questions that we ask in this study include: (i) Does intraspecific identity have an effect on deuterium uptake? (ii) How does belowground zone of influence in A. tridentata subspecies:cytotype groups decline with distance? (iii) Does the size of the neighbors have an effect on the water uptake by a target plant?

\section{Methods}

\section{$\underline{\text { Site Description }}$}

Measurements were made on an eight-year-old plantation of big sagebrush individuals that represented range-wide intraspecific variability, including three commonly recognized subspecies sourced from 55 populations across the western United States, and two cytotypes. The common garden was established in April 2010 with 468 individuals outplanted randomly with 1 by $1.5 \mathrm{~m}$ spacing intervals in a 28 by $24 \mathrm{~m}$ grid. A more detailed description of the experimental plot, including the associated climate 
covariates, is outlined in Chaney et al. (2017). Due to mortality, a total of 244 individuals of three subspecies were present at the time of our experiment. The crown size of the plants was measured one month prior to the experiment and further converted to a crown volume using a standard ellipsoid volume equation $V=4\left(\mathrm{r}_{1} \mathrm{r}_{2} \mathrm{r}_{3} \pi\right) / 3$.

\section{$\underline{\text { Plant Water Balance }}$}

Considering the variability of big sagebrush root activity in shallow soil horizons in response to sparse summer precipitation, we chose to conduct the tracer addition experiment in the beginning of June (1-3) 2018. This consideration was based on the possibility that shallow roots may fall into physiological dormancy during the dry period of the year (Germino and Reinhardt, 2014). We selected a rainless time window for the experiment to avoid a precipitation event interfering with the deuterium label concentration. To analyze soil moisture, a monthly record of soil moisture measurements preceding the experiment was obtained from a nearby weather station (Soil Climate Analysis Network: Orchard Range Site, https://www.wcc.nrcs.usda.gov/scan/). The moisture probes (Hydraprobe Analog (2.5 Volt) at 2,8, and 20 inches depths) are located in close proximity to the common garden and are representative of the long-term soil moisture content preceding the deuterium addition. To evaluate the overall water status of the plants during the experiment, we randomly selected 4 individuals for each subspecies:cytotype group $(\mathrm{n}=20)$ and measured pre-dawn and mid-day water potentials of foliated shoots on the day of the experiment using a Scholander pressure chamber (Model 1000, PMS Instrument Co., Corvallis, OR, USA). 


\section{Deuterium Labeling}

We split the common garden into 14 spatially-separated sub-plots. Each subplot corresponded to one deuterium oxide injection and a buffer distance that included the subject plants. Considering that lateral roots of A. tridentata rarely exceed $1.5 \mathrm{~m}$ from the base of plants (Reynolds and Fraley, 1989; Sturges, 1977), we used a 3 m radius around the injection point as a buffer zone. We introduced deuterium oxide solution in the center of each sub-plot, so the injection location was equidistant to the four nearest plants (Fig. 6). Each sub-plot would have had 24 plants in the original planting, but due to mortality there were between 8 and 17 plants per sub-plot. The proximity of individual plants to the source location in the centroid was at six distance increments $(0.9,1.7,2.3,2.6,2.7,3.4$ m) with this experimental design.

We prepared the labeling solution by mixing ${ }^{2} \mathrm{H}_{2}$ concentrate (99.8\%, Cambridge Isotope Laboratories, Inc.) and tap water $\left(\delta^{2} \mathrm{H}_{2} \sim-123 \%\right.$ ), which resulted in a solution of $\delta^{2} \mathrm{H}_{2} \sim 15950 \%$, a concentration assumed to be adequate for label detection based on a few pre-trials. Background $\delta^{2} \mathrm{H}_{2}$ concentrations in soils were $-106.8 \%$ o \pm 9.8 (mean \pm 1 $\mathrm{SD})$. We introduced one liter of the solution to the soil starting at a depth of $5 \mathrm{~cm}$ below the surface (beneath litter and annual weed roots that were excavated away). We poured the solution into through $0.11 \mathrm{~m}$ diameter plastic cylinders placed at the soil surface to prevent run-off and thereby force downward infiltration. Following label application, the volume of soil that became saturated under each injection location was estimated to be $\sim 0.006 \mathrm{~m}^{3}$, assuming a cylindrical plume to a depth of $0.2 \mathrm{~m}$. These estimates were empirically obtained from pre-trials on similar soils adjacent to the common garden, in which we were able to excavate around the injection point to visually assess how 
injections would disperse in the soil. Injections were made in the morning, and measurements of plant water status and $\delta^{2} \mathrm{H}_{2}$ were made $\sim 30$ hours later in the afternoon of the following day. This sampling time was estimated based on previous ${ }^{2} \mathrm{H}_{2}$ tracer experiments (e.g., Kulmatiski and Beard, 2013), and was also tested in pre-trial additions near the experimental site.

For xylem sampling, we collected branches with visible secondary growth that were typically $10 \mathrm{~cm}$ long (shorter from smaller plants), and about $0.6 \mathrm{~cm}$ in diameter. We removed the bark right after cutting the branch, wrapped the sample with parafilm, and placed it in an airtight glass vial, which was stored at $3^{\circ} \mathrm{C}$ until analysis (Grossiord et al., 2014; Lazarus and Germino, 2017). We used a Picarro Induction Module (IM) coupled to a CRDS isotopic analyzer (L2120-i, Picarro Inc., Santa Clara, CA, USA) to analyze the isotopic composition of water vapor extracted directly from xylem sections by induction heating, following Lazarus et al. (2016). We analyzed 3-8 sections per stem sample and averaged the final 2-3 readings to avoid memory bias from previous samples. Samples were weighed immediately after analysis and again after oven drying for 24 hours at $65^{\circ} \mathrm{C}$ to verify that all water had been removed during the analysis (data not shown). Lazarus et al. (2016) showed that no spectral interference from organic compounds occurred for big sagebrush stems analyzed by this method. Isotope ratios were standardized to the VSMOW/SLAP scale using isotopic water standards (Los Gatos Research, San Jose, CA, USA) introduced on dried-then-labeled sagebrush stem sections (Lazarus et al., 2016). 


\section{$\underline{\text { Data Analysis }}$}

We calculated the difference between the pre-treatment and post-treatment $\delta^{2} \mathrm{H}$ ratios in xylem water, which was our response in the statistical models. This variable indicated the amount of labeled water taken up by each plant. We discarded one outlier reading that was 13 standard deviations above the average difference between pre- and post-treatments.

The objective of our statistical models was to determine the effects of intraspecific variation and size-based crowding on the deuterium uptake rates. To answer questions (i) and (ii), we used the identity, size, and distance of plants from the label injection locations as predictors of deuterium uptake to quantify belowground zone of influence. We modeled the response using a modified negative exponential function with two parameters, the average uptake by subspecies:cytotype group and the rate of change in deuterium content with distance (Eq. 1):

$$
\text { Deuterium uptake }=\alpha e^{-D^{2} \beta} ;(1)
$$

where $\mathrm{D}$ is its distance from the centroid of the sub-plot, $\alpha$ is the intercept, and $\beta$ is the rate of decline in deuterium content with distance.

Both $\alpha$ and $\beta$ parameters were modeled as random effects with five categories corresponding to the five subspecies:cytotypes combinations. Random effects acknowledge the similarity between subspecies by estimating one shared variance parameter for all subspecies while allowing the coefficients to vary between groups (Gelman and Hill, 2006). In our case, modeling these parameters enabled us to address question (i) by quantifying variability in root spatial reach between cytotypes and subspecies. 
To answer question (iii), the effect of neighbors on uptake of the label, we subset the observations to include only the nearest neighbors of the deuterium source location. We excluded more distant plants for two reasons: (1) only the nearest neighbors were in an equal position to absorb the labeled water; (2) from the biological standpoint, the effect on resource competition imposed by distant individuals for the resource located at a centroid of the subplot is likely to be negligible, compared to the advantage of being spatially close to the source. Our competition model included the base (average) deuterium uptake by a target plant, and a ratio of cumulative neighbor crown volume to the crown volume of the target plant as an additive term, reflecting the relative aboveground physical space occupied by the neighbors compared to that of the target plant. We modeled the parameters as random effects corresponding to the three subspecies of A. tridentata (Eq. 2):

$$
\text { deuterium uptake }=\alpha_{0, i,[s]}+\alpha_{1, i}\left[\frac{1}{S_{i}} \sum_{j=1, j \neq i}^{4} S_{j}\right]
$$

where $\alpha_{0}$ is the average deuterium uptake with subspecies as a random effect, and $\alpha_{1}$ is a neighbor effect on the target plant uptake rate modeled as fixed effect with no pooling of variance.

We fit Hierarchical Bayesian models in R using Hamiltonian Monte Carlo algorithm from the 'rstan' package (R Core Team 2018, Stan Development Team 2018). To initialize the sampling, we chose-weakly informed priors (McElreath, 2016). The nonspatial predictors were standardized by centering them around the mean and dividing by two standard deviations (Gelman and Hill, 2006). For model selection, we used in-sample 
widely applicable information criterion (WAIC) scores and calculated mean absolute error (MAE) as a measure of model fit (Vehtari et al., 2017).

\section{Results}

Measurements of ambient soil moisture revealed that moisture content was relatively high and stable during the month preceding the experiment (Fig. 10). The leaf water potentials indicated that plant water status was variable but within the range tolerated by $A$. tridentata (Kolb and Sperry, 1999). There was a significant difference between the pre-dawn and mid-day water potentials $\left(\mathrm{r}^{2}=88 \%, \mathrm{~F}_{1,38}=281.3, \mathrm{p}=<0.001\right)$, but no differences among groups during the mid-day measurements $\left(\mathrm{r}^{2}=35 \%, \mathrm{~F}_{4,15}, \mathrm{p}=\right.$ 0.139) (Fig. 7). These results suggest that the observed subspecies:cytotype differences in label uptake would be attributed to differences in belowground zone of influence and not to differences in plant water status.

We modeled belowground zone of influence using a non-linear response function with an asymptote at zero. We found that a modified negative exponential regression had the best fit and highest predictive power when we considered size and distance predictors in linear and non-linear regressions (Table 2). Our negative exponential function revealed that the probability of plants taking up deuterated water steeply declined within the radius of two meters around the target plant. Our first hypothesis was partially supported by label uptake differences between subspecies:cyctotype groups. All dissimilarities, however, became negligible beyond the two-meter radius where deuterium uptake was estimated to be minimal for all subspecies. In the range of $0.9-1.5 \mathrm{~m}$ from the source, we found noticeable differences in deuterium absorption between subspecies:cytotype categories (Fig. 8). Notably, A.t. vaseyana:2x was associated with lower water uptake 
compared to other groups. Additionally, tetraploids within a subspecies, namely A.t. tridentata: $4 \mathrm{x}$ and A.t. vaseyana: $4 \mathrm{x}$, tended to have a higher average uptake and wider lateral reach compared to their diploid variants (Fig. 8). Although there was a large amount of uncertainty around the estimates, these results suggest that intraspecific variability in lateral root extent of $A$. tridentata may be related to cytotype and subspecies identity.

Contrary to our expectations, we did not find a discernable effect of the crowding ratio on deuterium uptake. Moreover, we excluded the size of the target plant as a separate predictor from the model because its effect was not detectable, and it did not improve the overall model fit. The estimated median of deuterium uptake under the average crowding pressure (i.e., intercept) was highest for A.t. tridentata, but the credibility intervals for all groups highly overlapped. We did not find a strong evidence that neighbors had an effect on deuterium uptake by a target plant. The median response to crowding of A.t. vaseyana and A.t. wyomingesis was very close to zero, and the effect on A.t. tridentata was negative at $-52 \%$ but with credibility intervals overlapping zero (95\%CI: -244, 138) (Fig. 9).

\section{Discussion}

Intraspecific variability in belowground plant architecture and spatial interactions is a key knowledge gap in current ecological literature. Here, we quantified belowground zone of influence for A. tridentata in a common garden setting, and experimentally tested if water uptake could underlie resource based-intraspecific interactions. Our experiment using deuterium tracer constitutes one of the few attempts to test ecophysiological mechanisms of water limitation in a common garden setting. We found that sub-specific 
groups of $A$. tridentata have different rates of water uptake from shallow soil horizons, suggesting intraspecific variability in structural and functional root architecture. Contrary to our expectations, we did not find that aboveground crown volume was a strong predictor of belowground zone of influence. Similarly, we found that cumulative crown volume of plant neighbors was not a strong predictor of water uptake. Instead, our results demonstrated that the differences in lateral extent of water uptake from shallow soils in A. tridentata were more related to the subspecies identity and ploidy level of target plants. These differences may have implications for subspecies' ecological responses to global changes including changing precipitation patterns and biological invasions (Germino et al., 2016; Knapp et al., 2008; Schwinning and Kelly, 2013).

The observed results generally agree with our understanding of big sagebrush ecology and its habitat preferences. Although big sagebrush can utilize water resources from shallow and deep soil horizons (Kolb and Sperry, 1999), intraspecific variation in root growth and functioning can affect this pattern. The lateral root extent in A.t. wyomingensis was higher compared to A.t. tridentata, which generally agrees with expectations based on the typical habitats occupied by these subspecies. The latter subspecies is typically found in drainages and expected to be adapted to deep soil profiles, while A.t. wyomingensis generally occupies plains with shallow soils (e.g., Shultz, 2009). Although we did not measure the vertical dimension of the roots, our experiment corroborates the pattern of habitat preferences based on intraspecific variation in lateral root extent. Differences in lateral root functioning between subspecies:cytotype groups of A. tridentata could also underlie differential patterns of surface water use. In particular, tetraploid subpopulations tended to show a wider lateral root extent, 
suggesting higher surface water use capacity (Fig. 11). The development and activity of lateral roots is highly relevant to $A$. tridentata performance under seasonal precipitation patterns in the Great Basin. The reproductive effort in this species occurs during the season with sporadic and unpredictable rain events during the summer and depends on the capacity of lateral roots to utilize limiting water resources from shallow soils (DePuit and Caldwell, 1973; Goldberg and Novoplansky, 1997). Based on our results, this trait was related to the ploidy effect that persisted across subspecies, as both A.t. vaseyana and A.t. tridentata tetraploids, juxtaposed with their diploid variants, had higher average uptake and slower rate of decline with distance. The presence and activity of lateral roots, located close to the soil surface, may also be important in context of long-term species coexistence and intraspecifc interactions (Ryel et al. 2010; Wilcox et al. 2012).

We found that the radius of lateral extent of root water uptake is largely limited to about two meters, however, we did not find a strong relationship between the crown size and the deuterium uptake. Size was a poor predictor both in the linear and non-linear models and did not improve model fit (Table 2). Likewise, the crowding effect by neighboring plants was indiscernible from zero suggesting that belowground water partitioning may be unrelated to aboveground crown volume. Because of this weak relationship, it is possible that belowground crowding may be important for resource acquisition but it was impossible to quantify with the data at hand. Big sagebrush is a perennial shrub with complex root system architecture (Germino and Reinhardt, 2014), and the experimental evidence from other species indicates that the root growth allocation is related to stress response and tolerance levels (Xiong et al., 2006; Xu et al., 2015). In our study, population-specific variation in stress tolerance may underlie the overall lack 
of a strong relationship between crown and root presence in shallow soil horizon based on deuterium uptake rates. Current evidence by allometric models relating above- and belowground parts in A. tridentata suggests crown measurements could be used to coarsely estimate total root biomass (Cleary et al., 2008). However, patterns of soil resource uptake are likely more complex and related to the spatial arrangement and functioning of roots (Kulmatiski et al., 2017).

The overall lateral root extent in different subspecies:cytotype groups of big sagebrush has implications for energy allocation and stress tolerance. In terms of drought response and eco-hydrological strategy, Araya et al. (2011) outlines a clear trade-off between tolerance of aeration stress and drought stress. The underlying mechanisms behind drought response in terms of root plasticity suggests a trade-off between drought tolerance and, e.g., nutrient uptake by prioritizing vertical root growth and thereby limiting access to mineral nutrients in more aerated shallow soil horizons (Xiong et al., 2006). This mechanism involves abscisic acid (ABA), a plant stress hormone that can inhibit lateral root elongation by allocating available resources to the growth of the main root to increase water supply from deeper soils. In the context of our study, this pattern may suggest that polyploids of $A$. tridentata, which generally have higher capacity for drought tolerance, would be able to minimize this trade-off between nutrient and water access compared to more drought-sensitive diploid plants. We found that A.t. wyomingesis:4x and A.t. tridentata:4x were associated with wider lateral root extent, while A.t. tridentata:2x seemed more likely to be allocating resources to root growth along the vertical axis (Knick and Connelly, 2011). Moreover, the results for A.t. vaseyana:2x suggest that this subspecies:cytotype group has little root growth in the 
horizontal direction while at the same time might have limited ability to reach deeper soil based on the average performance and survival in this group (Chaney et al., 2017). These intraspecific traits also support previous evidence of subspecies differences in response to the gradient of drought stress by Kolb and Sperry (1999).

Deuterium tracer experiments provide an opportunity to experimentally test spatial and temporal patterns of belowground processes, including neighbor interactions. In our study, we aimed to understand how individuals of $A$. tridentata respond to a local water resource pulse in an arid environment, and how the resource was spatially distributed among neighboring individuals. In congruence with the finding from an excavating study of Larrea tridentata (Brisson and Reynolds, 1994), we did not find a strong evidence that the size of a target plant and neighbors influenced patterns in resource acquisition. This finding, however, could be an artifact of: (i) inadequate sample size for the neighborhood model, and especially for the subspecies with high mortality and a relatively small representation (e.g., A.t. vaseyana), or (ii) common garden experimental design. For example, if plants are outplanted at the same time, we would expect that their root system develops unobstructed until their roots interface with those of the neighbors. This pattern could potentially result in a relatively proportional occupancy of the shallow soil space minimizing asymmetric resource partitioning which could underlie the weak effect of aboveground neighbor size in our models. Subspecies that invest more into their lateral roots would have higher root density within their zone of influence but may not necessarily have a competitive advantage detectable from a time snapshot of a temporal process such as resource acquisition (Kulmatiski et al., 2017). An experiment in a natural system, including larger sample size and a time series sampling 
following the treatment could disentangle this uncertainty. On the other hand, our results clearly indicate that multiple plants can benefit from a relatively small local water pulse, and the observed variability in deuterium uptake may be dependent upon the root density in the resource island. This also suggests a that the roots of neighboring A. tridentata individuals in the common garden setting may have a high degree of overlap, which was previously documented for A.t. vaseyana (Krannitzi and Caldwell, 1995).

Our experiment illustrates how deuterium experiments can be used to evaluate a species' belowground zone of influence and local interactions such as consumptive competition. The results complement the existing knowledge of belowground root architecture in A. tridentata obtained from excavating studies by evaluating belowground zone of influence based on a physiological activity of a target plant (Reynolds and Fraley, 1989; Sturges, 1977). Moreover, our results indicate some intraspecific differences and trade-offs on an eco-hydrological gradient in light of root spatial architecture of $A$. tridentata. In the context of global changes including shifts in precipitation patterns (Knapp et al., 2008), understanding plant root architecture and resource partitioning patterns in arid environments may have implications for seed sourcing and restoration decisions. Our study also suggests several potential research directions in the applied and theoretical contexts. Some questions may include eco-hydrological niche partitioning and intraspecific coexistence, the effect of evolutionary processes, such as polyploidy, on resource partitioning, or the need to consider spatial interactions among individuals in common garden trials. 


\section{REFERENCES}

Adler, P.B., Ellner, S.P., Levine, J.M., 2010. Coexistence of perennial plants: an embarrassment of niches. Ecology Letters 13, 1019-1029.

Araya, Y.N., Silvertown, J., Gowing, D.J., McConway, K.J., Linder, H.P., Midgley, G., 2011. A fundamental, eco-hydrological basis for niche segregation in plant communities. New Phytologist 189, 253-258.

Belcher, J.W., Keddy, P.A., Twolan-Strutt, L., 1995. Root and Shoot Competition Intensity Along a Soil Depth Gradient. Journal of Ecology 83, 673-682.

Brisson, J., Reynolds, J.F., 1994. The Effect of Neighbors on Root Distribution in a Creosotebush (Larrea Tridentata) Population. Ecology 75, 1693-1702.

Casper, B.B., Jackson, R.B., 1997. Plant Competition Underground. Annual Review of Ecology and Systematics 28, 545-570.

Casper, B.B., Schenk, H.J., Jackson, R.B., 2003. Defining a Plant's Belowground Zone of Influence. Ecology 84, 2313-2321.

Chaney, L., Richardson, B.A., Germino, M.J., 2017. Climate drives adaptive genetic responses associated with survival in big sagebrush (Artemisia tridentata). Evol Appl 10, 313-322.

Chapin III, F.S., Zavaleta, E.S., Eviner, V.T., Naylor, R.L., Vitousek, P.M., Reynolds, H.L., Hooper, D.U., Lavorel, S., Sala, O.E., Hobbie, S.E., Mack, M.C., Díaz, S., 2000. Consequences of changing biodiversity. Nature 405, 234-242.

Chesson, P., 2018. Updates on mechanisms of maintenance of species diversity. Journal of Ecology 106, 1773-1794.

Chesson, P., Gebauer, R.L.E., Schwinning, S., Huntly, N., Wiegand, K., Ernest, M.S.K., Sher, A., Novoplansky, A., Weltzin, J.F., 2004. Resource pulses, species 
interactions, and diversity maintenance in arid and semi-arid environments.

Oecologia 141, 236-253.

Cleary, M.B., Pendall, E., Ewers, B.E., 2008. Testing sagebrush allometric relationships across three fire chronosequences in Wyoming, USA. Journal of Arid Environments 72, 285-301.

DePuit, E.J., Caldwell, M.M., 1973. Seasonal Pattern of Net Photosynthesis of Artemisia tridentata. American Journal of Botany 60, 426-435.

DiCristina, K., Germino, M., 2006. CORRELATION OF NEIGHBORHOOD RELATIONSHIPS, CARBON ASSIMILATION, AND WATER STATUS OF SAGEBRUSH SEEDLINGS ESTABLISHING AFTER FIRE. Western North American Naturalist 66, 441-449.

Donovan, L.A., Ehleringer, J.R., 1994. Water Stress and Use of Summer Precipitation in a Great Basin Shrub Community. Functional Ecology 8, 289-297.

Evans, R.D., Black, R.A., Link, S.O., 1991. Reproductive Growth During Drought in Artemisia tridentata Nutt. Functional Ecology 5, 676-683.

Flanagan, L.B., Ehleringer, J.R., 1991. Stable Isotope Composition of Stem and Leaf Water: Applications to the Study of Plant Water Use. Functional Ecology 5, 270277.

Fowler, N., 1986. The Role of Competition in Plant Communities in Arid and Semiarid Regions. Annual Review of Ecology and Systematics 17, 89-110.

Gelman, A., Hill, J., 2006. Data Analysis Using Regression and Multilevel/Hierarchical Models. Cambridge University Press.

Germino, M.J., Chambers, J.C., Brown, C.S. (Eds.), 2016. Exotic Brome-Grasses in Arid and Semiarid Ecosystems of the Western US: Causes, Consequences, and Management Implications, Springer Series on Environmental Management. Springer International Publishing. 
Germino, M.J., Moser, A.M., Sands, A.R., 2018. Adaptive variation, including local adaptation, requires decades to become evident in common gardens. Ecological Applications.

Germino, M.J., Reinhardt, K., 2014. Desert shrub responses to experimental modification of precipitation seasonality and soil depth: relationship to the two-layer hypothesis and ecohydrological niche. J Ecol 102, 989-997.

Goldberg, D., Novoplansky, A., 1997. On the Relative Importance of Competition in Unproductive Environments. Journal of Ecology 85, 409-418.

Goldberg, D.E., 1990. Components of resource competition in plant communities. Components of resource competition in plant communities. 27-49.

Groot, G.A. de, Zuidema, P.A., Groot, H. de, During, H.J., 2012. Variation in ploidy level and phenology can result in large and unexpected differences in demography and climatic sensitivity between closely related ferns. American Journal of Botany 99, 1375-1387.

Grossiord, C., Gessler, A., Granier, A., Berger, S., Bréchet, C., Hentschel, R., Hommel, R., Scherer-Lorenzen, M., Bonal, D., 2014. Impact of interspecific interactions on the soil water uptake depth in a young temperate mixed species plantation. Journal of Hydrology 519, 3511-3519.

Hart, S.P., Schreiber, S.J., Levine, J.M., 2016. How variation between individuals affects species coexistence. Ecology Letters 19, 825-838.

Havens, K., Vitt, P., Still, S., Kramer, A.T., Fant, J.B., Schatz, K., 2015. Seed Sourcing for Restoration in an Era of Climate Change. Natural Areas Journal 35, 122-133.

Kadmon, R., 1995. Plant Competition along Soil Moisture Gradients: A Field Experiment with the Desert Annual Stipa Capensis. Journal of Ecology 83, 253-262.

Knapp, A.K., Beier, C., Briske, D.D., Classen, A.T., Luo, Y., Reichstein, M., Smith, M.D., Smith, S.D., Bell, J.E., Fay, P.A., Heisler, J.L., Leavitt, S.W., Sherry, R., Smith, B., Weng, E., 2008. Consequences of More Extreme Precipitation Regimes for Terrestrial Ecosystems. BioScience 58, 811-821. 
Knick, S.T., Connelly, J.W., 2011. Greater Sage-GrouseEcology and Conservation of a Landscape Species and Its Habitats. University of California Press.

Kolb, K.J., Sperry, J.S., 1999. Differences in Drought Adaptation between Subspecies of Sagebrush (Artemisia Tridentata). Ecology 80, 2373-2384.

Krannitzi, P.G., Caldwell, M.M., 1995. Root growth responses of three Great Basin perennials to intra and interspecific contact with other roots. Flora 190, 161-167.

Kulmatiski, A., Adler, P.B., Stark, J.M., Tredennick, A.T., 2017. Water and nitrogen uptake are better associated with resource availability than root biomass. Ecosphere 8, e01738.

Kulmatiski, A., Beard, K., 2013. Root niche partitioning among grasses, saplings, and trees measured using a tracer technique. Oecologia 171, 25-37.

Lazarus, B.E., Germino, M.J., 2017. Methodological considerations regarding online extraction of water from soils for stable isotope determination. Rapid Communications in Mass Spectrometry 31, 1677-1680.

Lazarus, B.E., Germino, M.J., Vander Veen, J.L., 2016. Online induction heating for determination of isotope composition of woody stem water with laser spectrometry: a methods assessment. Isotopes in Environmental and Health Studies 52, 309-325.

Leffler, A.J., Ivans, C.Y., Ryel, R.J., Caldwell, M.M., 2004. Gas exchange and growth responses of the desert shrubs Artemisia tridentata and Chrysothamnus nauseosus to shallow- vs. deep-soil water in a glasshouse experiment. Environmental and Experimental Botany 51, 9-19.

Leger, E.A., 2008. THE ADAPTIVE VALUE OF REMNANT NATIVE PLANTS IN INVADED COMMUNITIES: AN EXAMPLE FROM THE GREAT BASIN. Ecological Applications 18, 1226-1235.

Li, W.-L., Berlyn, G.P., Ashton, P.M.S., 1996. Polyploids and their structural and PHYSIOLOGICAL CHARACTERISTICS RELATIVE TO WATER DEFICIT IN BETULA PAPYRIFERA (Betulaceae). American Journal of Botany 83, 15-20. 
Loik, M.E., 2007. Sensitivity of water relations and photosynthesis to summer precipitation pulses for Artemisia tridentata and Purshia tridentata. Plant Ecology 191, 95-108.

Loik, M.E., Breshears, D.D., Lauenroth, W.K., Belnap, J., 2004. A multi-scale perspective of water pulses in dryland ecosystems: climatology and ecohydrology of the western USA. Oecologia 141, 269-281.

Maherali, H., Walden, A.E., Husband, B.C., 2009. Genome duplication and the evolution of physiological responses to water stress. New Phytologist 184, 721-731.

McElreath, R., 2016. Statistical Rethinking: A Bayesian Course with Examples in R and Stan. CRC Press.

Miglia, K.J., McArthur, E.D., Redman, R.S., Rodriguez, R.J., Zak, J.C., Freeman, D.C., 2007. Genotype, soil type, and locale effects on reciprocal transplant vigor, endophyte growth, and microbial functional diversity of a narrow sagebrush hybrid zone in Salt Creek Canyon, Utah. American Journal of Botany 94, 425436.

Miriti, M.N., Wright, S.J., Howe, H.F., 2001. The Effects of Neighbors on the Demography of a Dominant Desert Shrub (ambrosia Dumosa). Ecological Monographs 71, 491-509.

Petrone Mendoza, S., Lascoux, M., Glémin, S., 2018. Competitive ability of Capsella species with different mating systems and ploidy levels. Ann Bot 121, 12571264.

R Core Team, 2018. R: A language and environment for statistical computing. $\mathrm{R}$ Foundation for Statistical Computing, Vienna, Austria. https://www.Rproject.org/.

Rau, B.M., Johnson, D.W., Blank, R.R., Lucchesi, A., Caldwell, T.G., Schupp, E.W., 2011. Transition From Sagebrush Steppe to Annual Grass (Bromus tectorum): Influence on Belowground Carbon and Nitrogen. Rangeland Ecology \& Management 64, 139-147. 
Reynolds, T.D., Fraley, L., 1989. Root profiles of some native and exotic plant species in Southeastern Idaho. Environmental and Experimental Botany 29, 241-248.

Richardson, B.A., Chaney, L., 2018. Climate-based seed transfer of a widespread shrub: population shifts, restoration strategies, and the trailing edge. Ecological Applications 28, 2165-2174.

Richardson, B.A., Page, J.T., Bajgain, P., Sanderson, S.C., Udall, J.A., 2012. Deep sequencing of amplicons reveals widespread intraspecific hybridization and multiple origins of polyploidy in big sagebrush (Artemisia tridentata; Asteraceae). Am. J. Bot. 99, 1962-1975.

Ryel, R.J., Leffler, A.J., Ivans, C., Peek, M.S., Caldwell, M.M., 2010. Functional Differences in Water-Use Patterns of Contrasting Life Forms in Great Basin Steppelands. Vadose Zone Journal 9, 548.

Schenk, H.J., 2006. Root competition: beyond resource depletion. Journal of Ecology 94, 725-739.

Schenk, J.H., Mahall, B.E., 2002. Positive and negative plant interactions contribute to a north-south-patterned association between two desert shrub species. Oecologia $132,402-410$.

Schwinning, S., Kelly, C.K., 2013. Plant competition, temporal niches and implications for productivity and adaptability to climate change in water-limited environments. Functional Ecology 27, 886-897.

Shultz, L.M., 2009. Monograph of Artemisia Subgenus Tridentatae (AsteraceaeAnthemideae). Systematic Botany Monographs 89, 1-131.

Stan Development Team, 2018. RStan: the R interface to Stan. R package version 2.18.2. http://mc-stan.org/.

Sturges, D.L., 1977. Soil Water Withdrawal and Root Characteristics of Big Sagebrush. American Midland Naturalist 98, 257. 
Tilman, D., Knops, J., Wedin, D., Reich, P., Ritchie, M., Siemann, E., 1997. The Influence of Functional Diversity and Composition on Ecosystem Processes. Science 277, 1300-1302.

Uriarte, M., Menge, D., 2018. Variation between individuals fosters regional species coexistence. Ecology Letters 21, 1496-1504.

Vehtari, A., Gelman, A., Gabry, J., 2017. Practical Bayesian model evaluation using leave-one-out cross-validation and WAIC. Stat Comput 27, 1413-1432.

Van Laere, K., França, S.C., Vansteenkiste, H., Van Huylenbroeck, J., Steppe, K., Van Labeke, M.-C., 2011. Influence of ploidy level on morphology, growth and drought susceptibility in Spathiphyllum wallisii. Acta Physiol Plant 33, 11491156.

Wilcox, B.P., Turnbull, L., Young, M.H., Williams, C.J., Ravi, S., Seyfried, M.S., Bowling, D.R., Scott, R.L., Germino, M.J., Caldwell, T.G., Wainwright, J., 2012. Invasion of shrublands by exotic grasses: ecohydrological consequences in cold versus warm deserts. Ecohydrology 5, 160-173.

Xiong, L., Wang, R.-G., Mao, G., Koczan, J.M., 2006. Identification of Drought Tolerance Determinants by Genetic Analysis of Root Response to Drought Stress and Abscisic Acid. Plant Physiology 142, 1065-1074.

Xu, W., Cui, K., Xu, A., Nie, L., Huang, J., Peng, S., 2015. Drought stress condition increases root to shoot ratio via alteration of carbohydrate partitioning and enzymatic activity in rice seedlings. Acta Physiologiae Plantarum 37. 


\section{Figures}

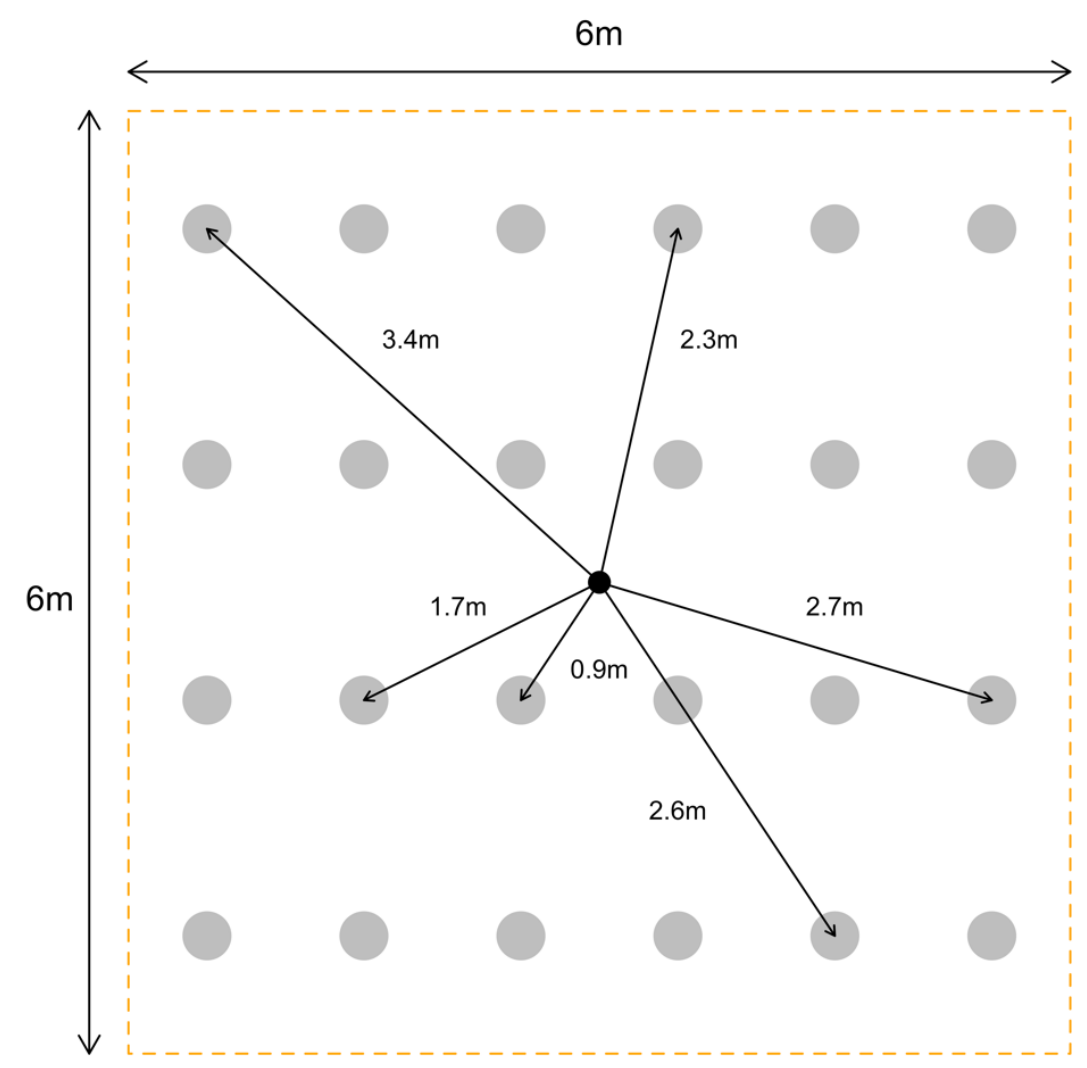

Figure 6: A diagram of an experimental unit in Orchard common garden. The centroid of the plot is a location where deuterium enriched water was introduced, the gray points show the grid of plants, and the arrows indicate a distance of each plant to the source location. 

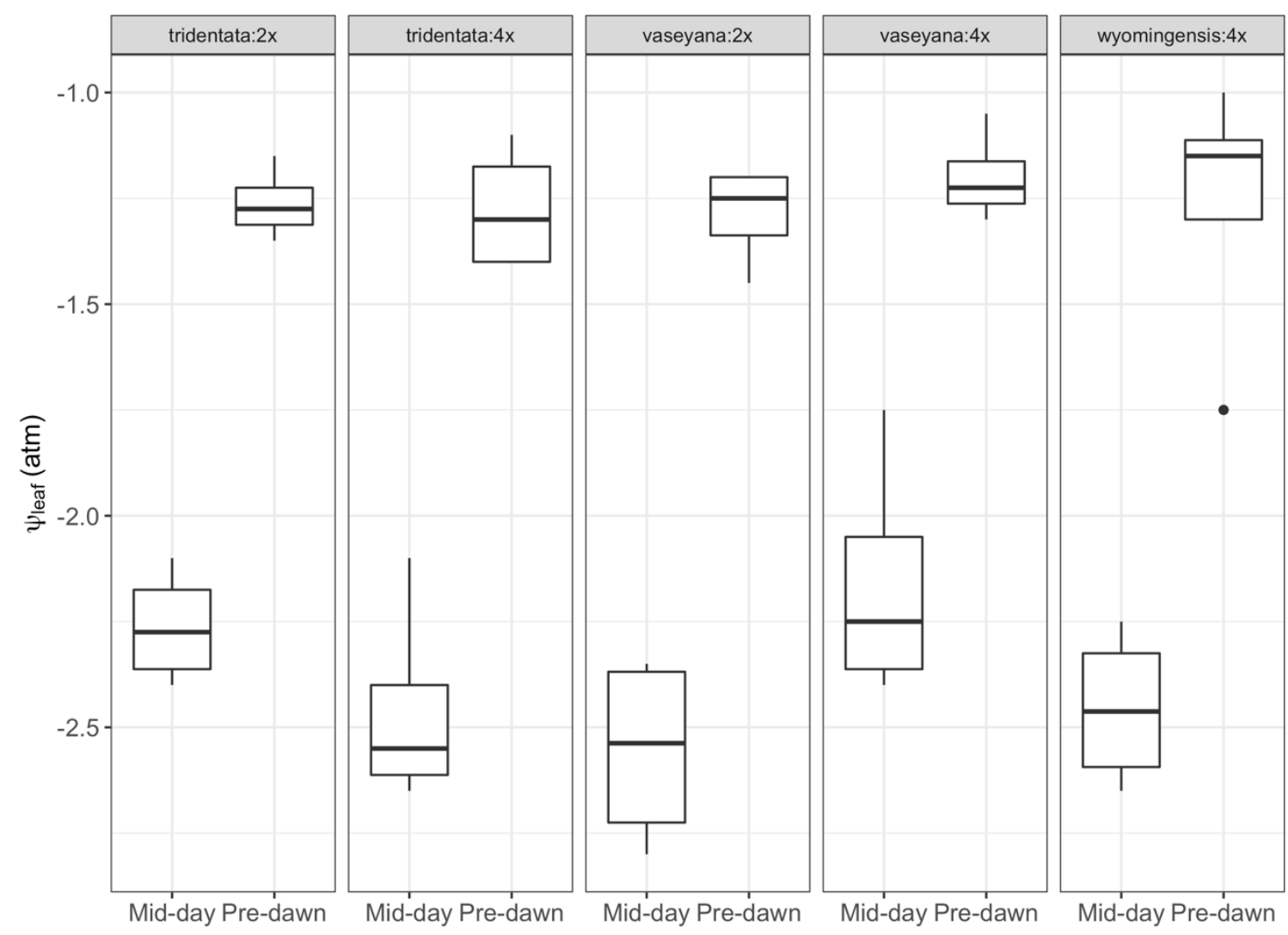

Figure 7: Water status of $A$. tridentata plants in Orchard common garden during the deuterium tracer experiment. The values are shown for pre-dawn and mid-day leaf water potential measurements for five different subspecies:cytotype groups of big sagebrush. Lower values represent higher water stress. 


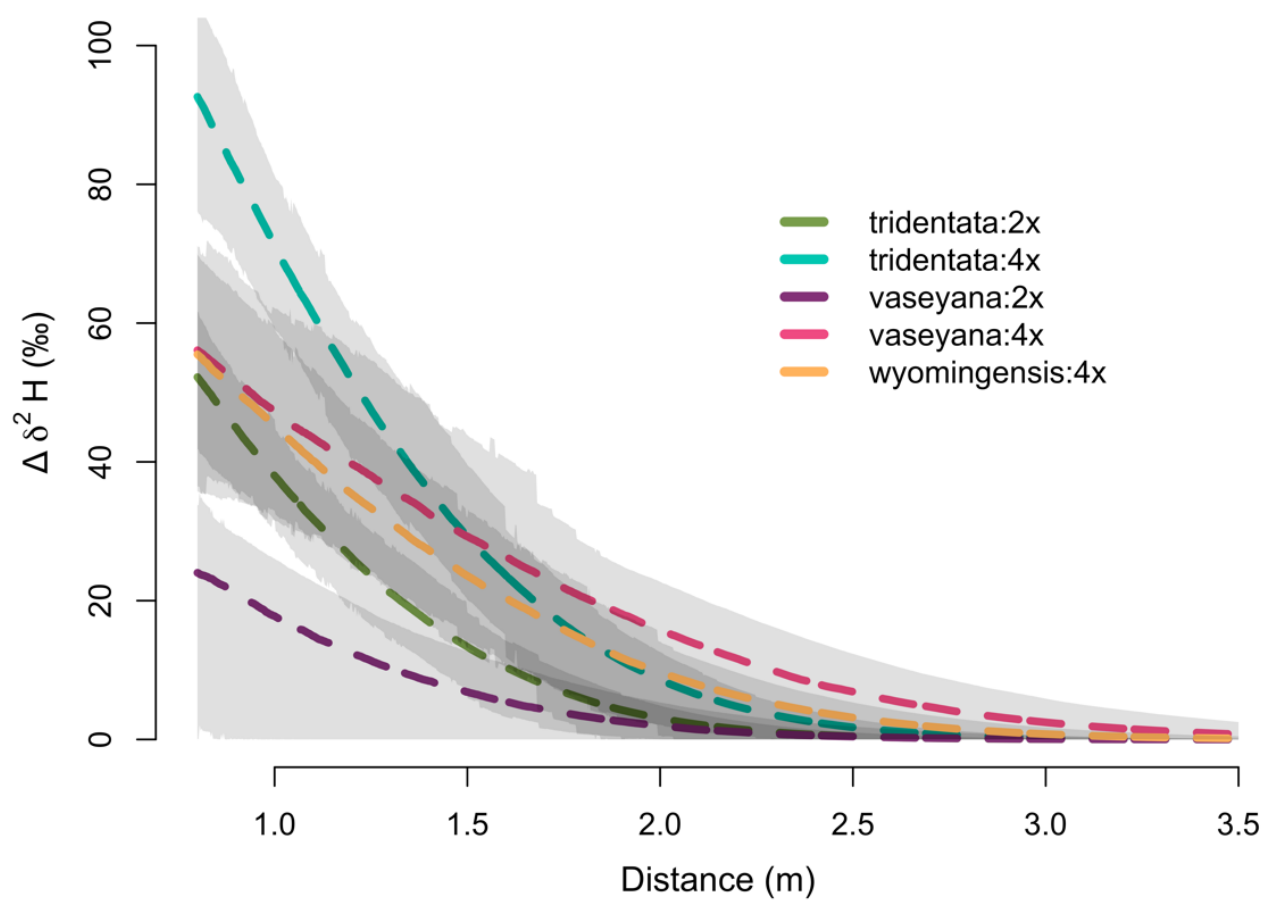

Figure 8: $\quad$ A. tridentata uptake of deuterium $\left({ }^{2} \mathrm{H}_{2} \mathrm{O}\right)$ enriched water as a function of distance from the source location and plant size. The label was introduced into plant interspaces in Orchard common garden in Spring 2018. The vertical axis indicates the change in deuterium ratio between the pre- and post-treatment. Different colors indicate subspecies:cytotype identity of big sagebrush, and the gray areas represent one SD around the posterior mean. 

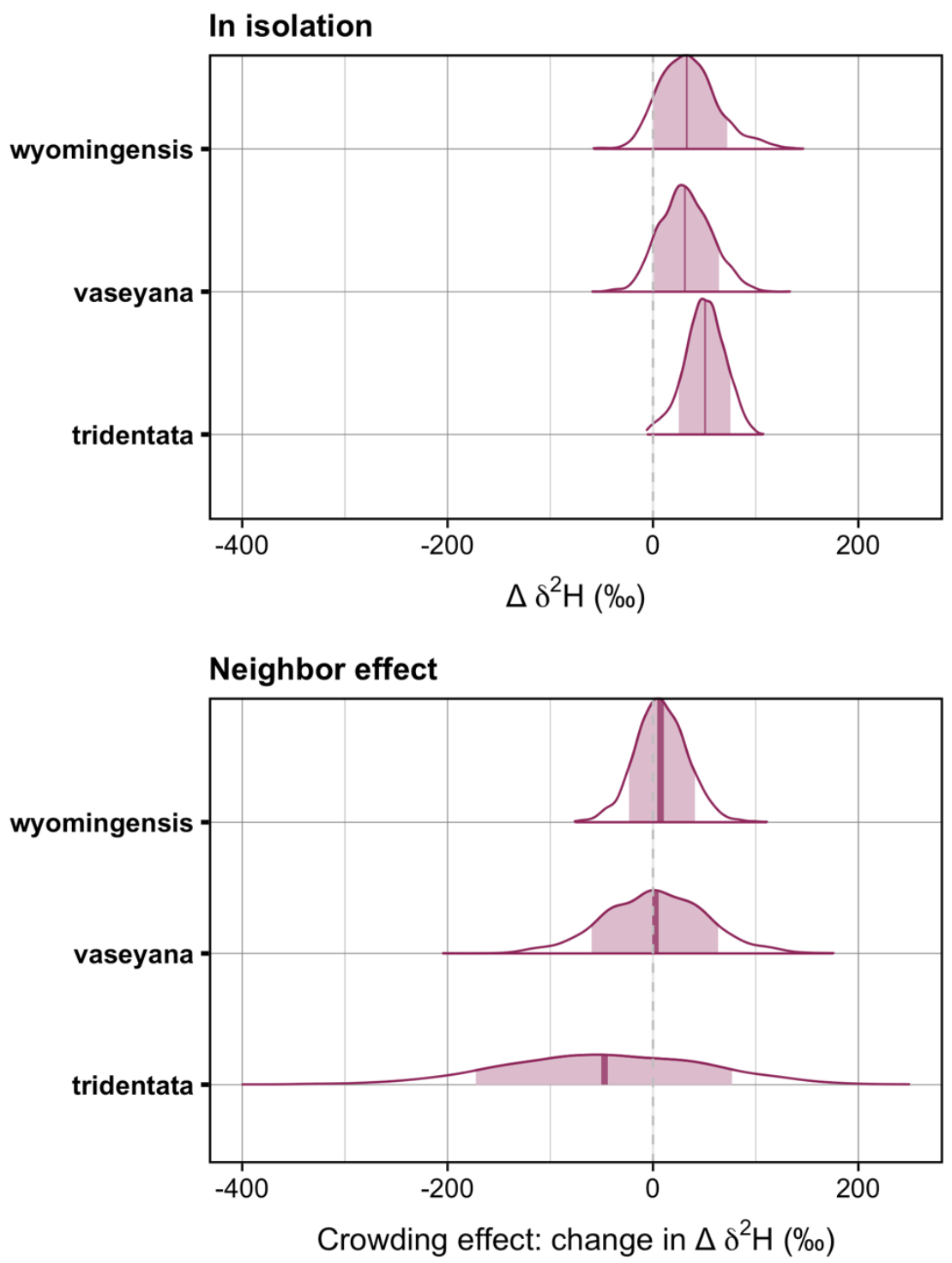

Figure 9: $\quad$ Posterior distribution of the average deuterium uptake by a target plant (upper plate). The lower plate shows the crowding effect on the label uptake in isolation under 2 SD increase in crowding ratio. The categories correspond to three subspecies of A. tridentata (tridentata, vaseyana, and wyomingensis). 


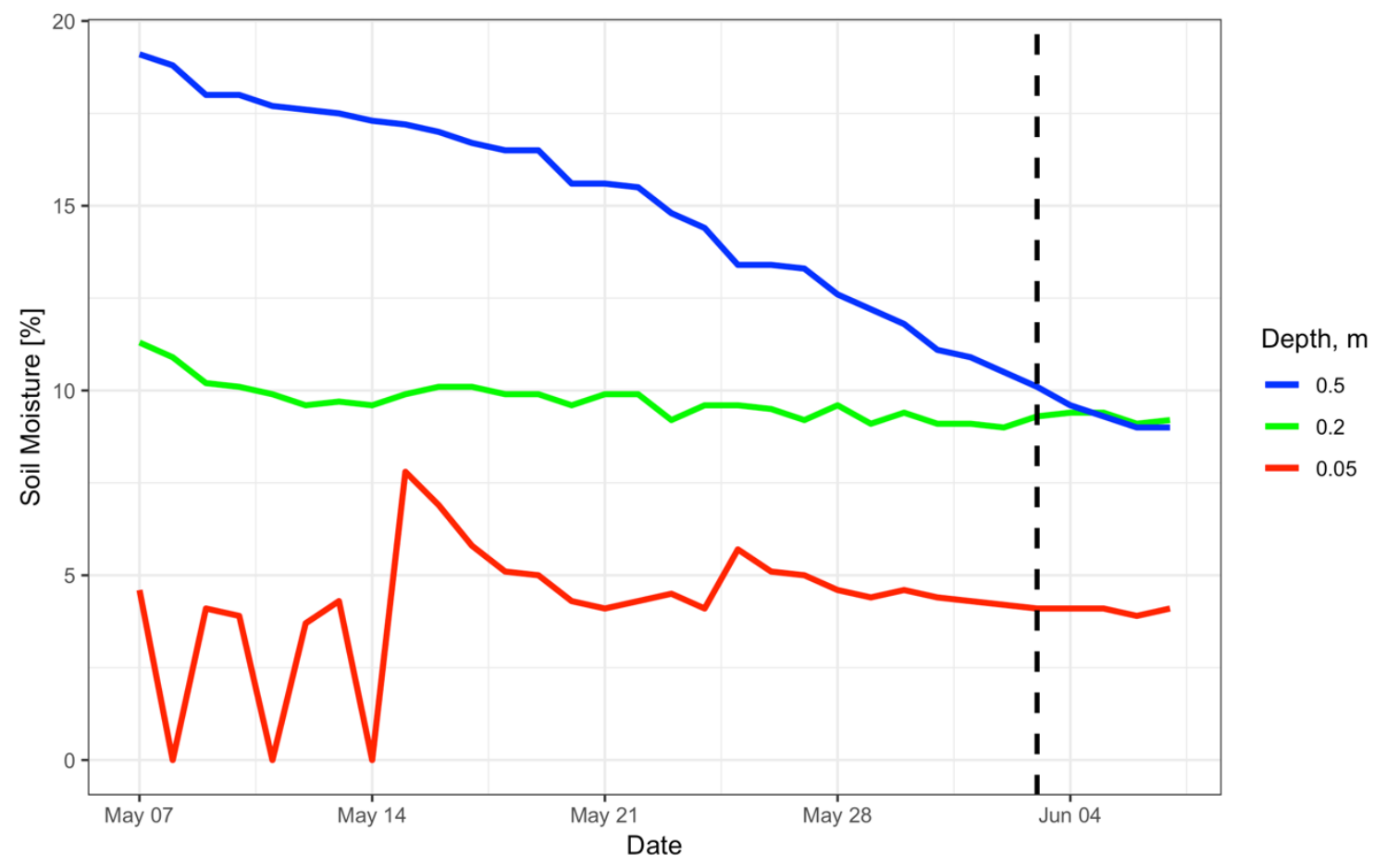

Figure 10: A line plot representing soil volumetric moisture readings at three soil depths over the period of one month preceding the labeling experiment. The vertical dashed line indicates the day of deuterium addition. 


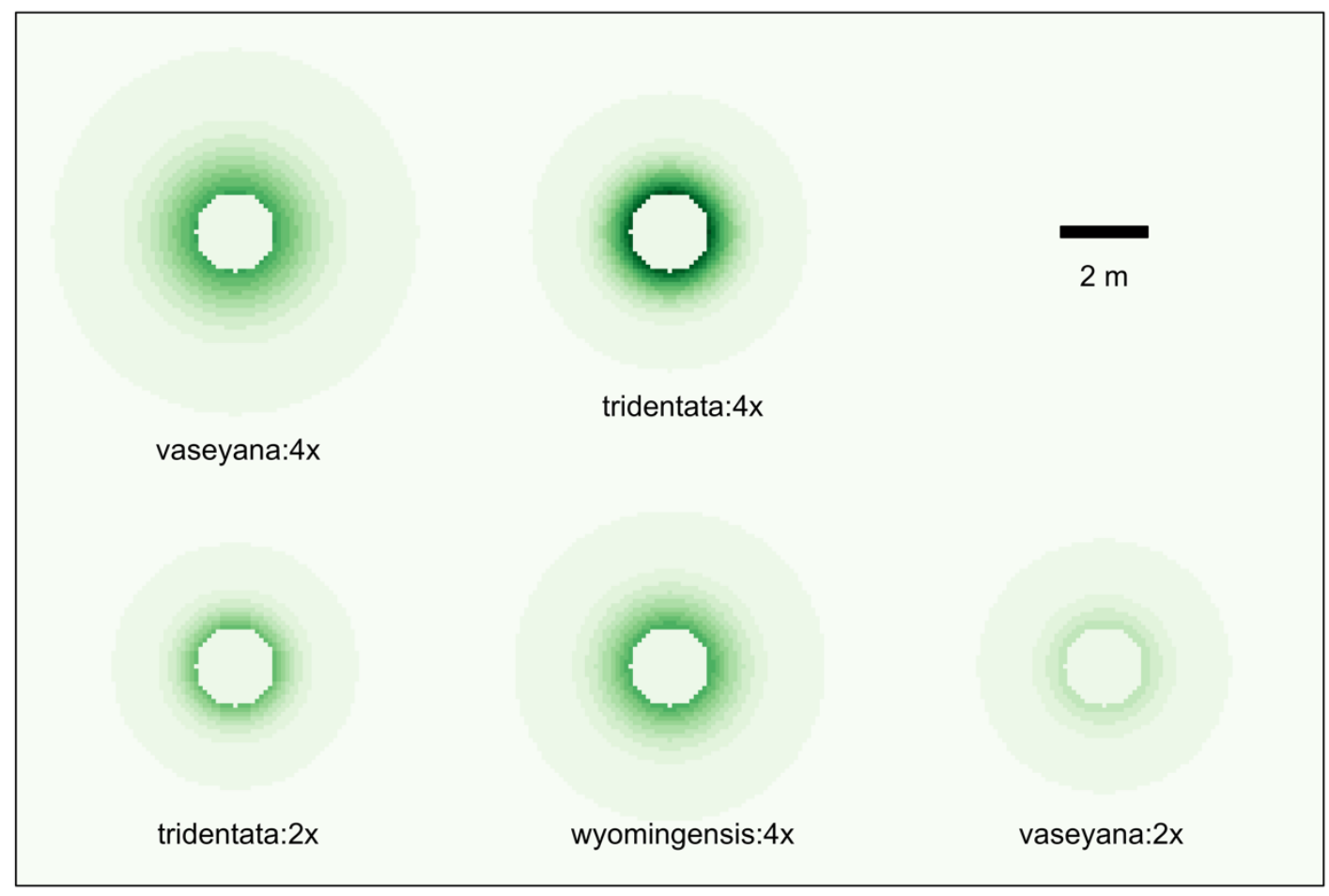

Figure 11: Predicted belowground zone of influence of $A$. tridentata subspecies:cytotype groups in Orchard common garden. The figures correspond to deuterium content where higher colour intensity indicates higher water uptake from shallow $5-25 \mathrm{~cm}$ soil horizon. Projections $<0.9 \mathrm{~m}$ were excluded (empty centers) due to out of range model predictions. 
Tables

Table 2: $\quad$ Model evaluation comparing the fit of linear and non-linear regressions of deuterium uptake.

\begin{tabular}{llllll}
\hline \multicolumn{1}{c}{ Equation } & Model & WAIC & R2 & RMSE & MAE \\
\hline$\alpha_{[\mathrm{s}]}+\beta_{[\mathrm{s}]} * \mathrm{D}$ & Linear & 1772.1 & 0.229 & 37.24 & 22.04 \\
$\alpha_{[\mathrm{s}]}+\beta_{[\mathrm{s}]} * \mathrm{D}+\boldsymbol{\theta}_{[\mathrm{s}]} * \mathrm{~S}$ & Linear & 1780.4 & 0.233 & 37.14 & 22.01 \\
$\alpha_{[\mathrm{s}]} * \exp \left(-\mathrm{D} * \beta_{[\mathrm{s}]}\right)$ & Negative exp & 1758.6 & 0.295 & 35.63 & 20.86 \\
$\alpha_{[\mathrm{s}]} *\left(\mathrm{~S} / \exp \left(-\mathrm{D}^{2} * \beta_{[\mathrm{s}]}\right)\right.$ & Non-linear & 1791.7 & 0.109 & 40.04 & 21.64 \\
$\alpha_{[\mathrm{s}]} * \exp \left(-\mathrm{D}^{2} * \beta_{[\mathrm{s}]}\right)$ & Non-linear & 1751.8 & 0.33 & 34.7 & 20.3 \\
$\alpha_{[\mathrm{s}]} * \exp \left(-\mathrm{D}^{2} *\left(1 / \mathrm{sqrt}(\mathrm{S}) * \beta_{[\mathrm{s}]}\right)\right.$ & Non-linear & 1758.3 & 0.303 & 35.39 & 21.15 \\
\hline
\end{tabular}


APPENDIX A

Supplementary Figures: Chapter One 


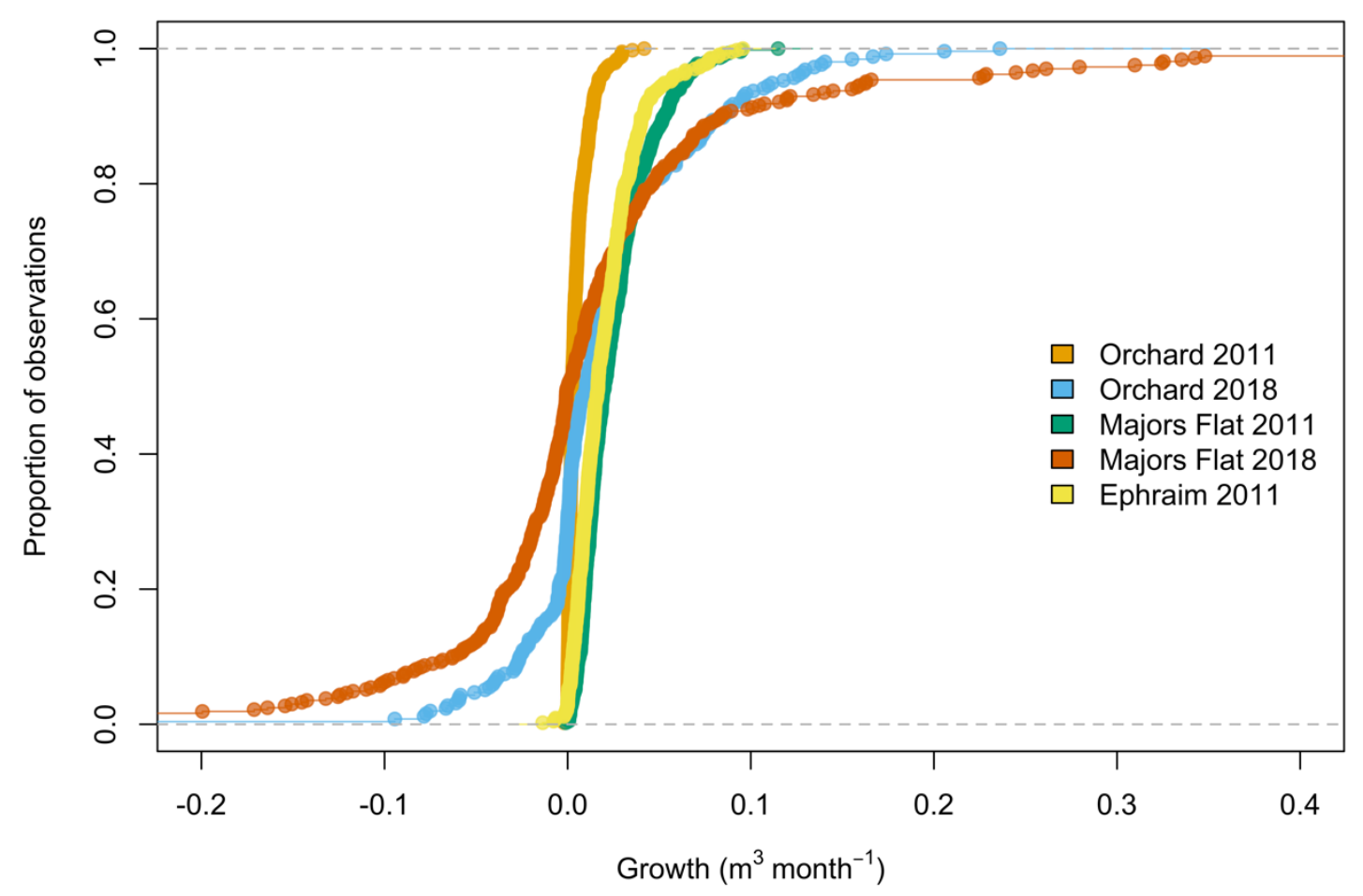

Figure S1: An empirical cumulative density function (ECDF) plot showing the distribution of relative growth rate (RGR) of $A$. tridentata in three common gardens. The RGR is calculated using 2011 census interval for all three sites (Orchard, Majors Flat, and Ephraim), and 2018 census interval for Orchard Majors Flat sites. The RGR is scaled to a monthly time step, and each point represents an individual plant. 

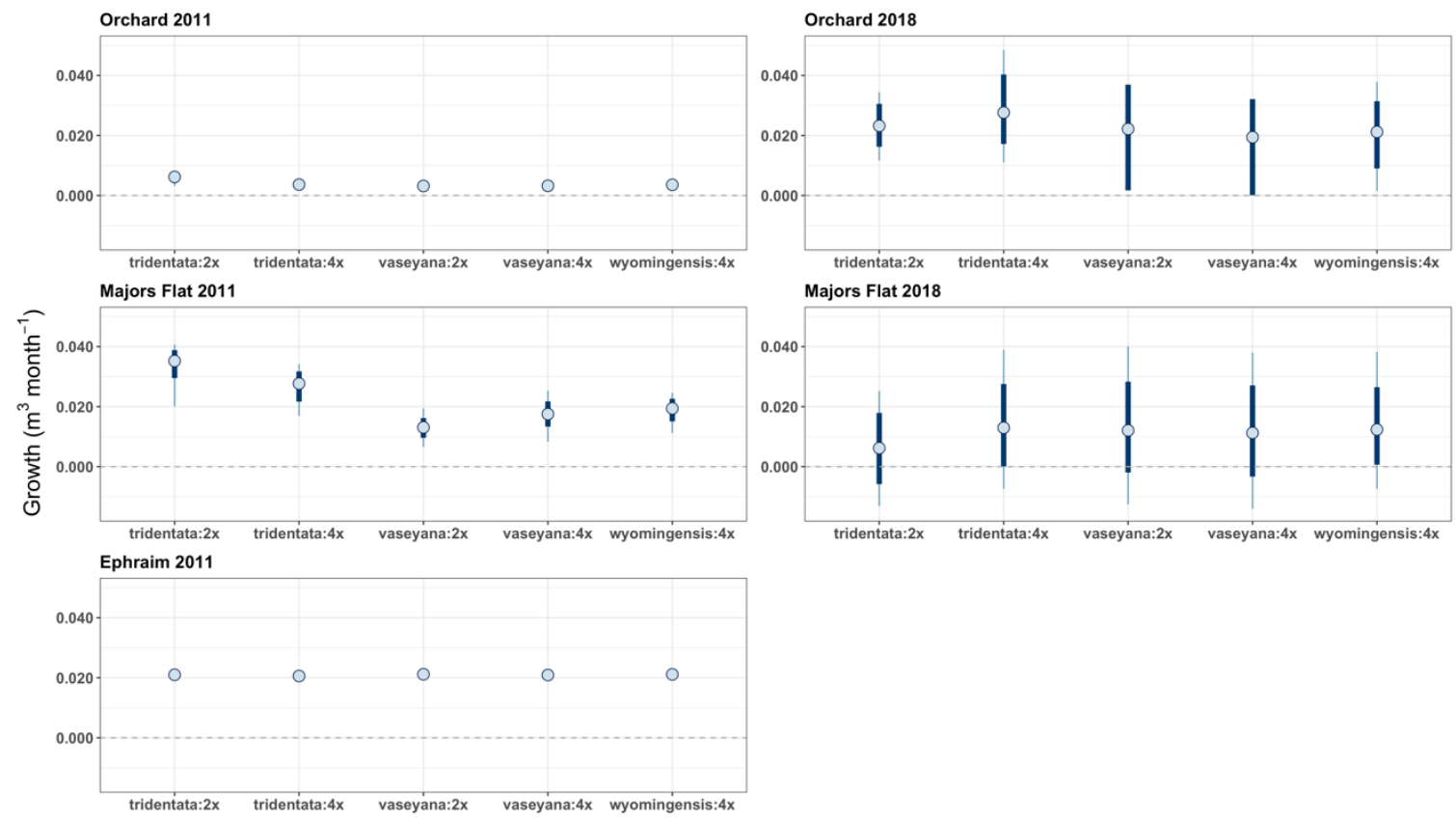

Figure S2: $\quad$ Posterior samples representing the intrinsic relative growth rates of $A$. tridentata in three common gardens. Thick lines represent $80 \% \mathrm{CI}$, thinner lines indicate $95 \% \mathrm{CI}$, and the dots are the medians of the posterior distributions. The categories on the $x$ axis represent five analyzed subspecies:cytotype groups of $A$. tridentata. 


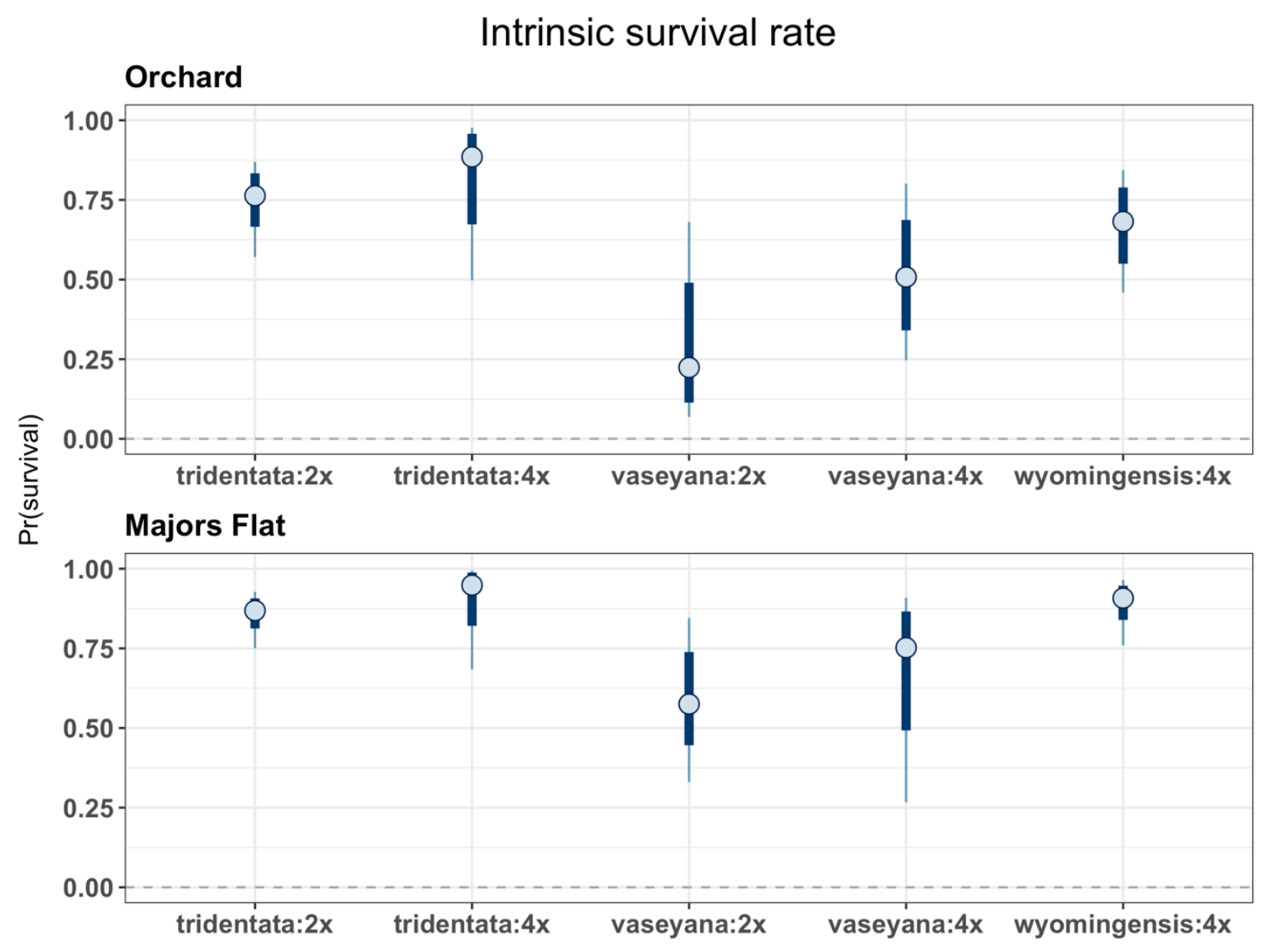

Figure S3: Posterior samples that represent the intrinsic probability of survival of $A$. tridentata in Orchard and Major Flats common gardens, using the census interval between 2012 and 2018. The $x$ axis represents five subspecific categories of A. tridentata. Thick lines represent $80 \% \mathrm{CI}$, while thinner lines indicate $95 \% \mathrm{CI}$, and the dots are the medians of the posterior samples. 


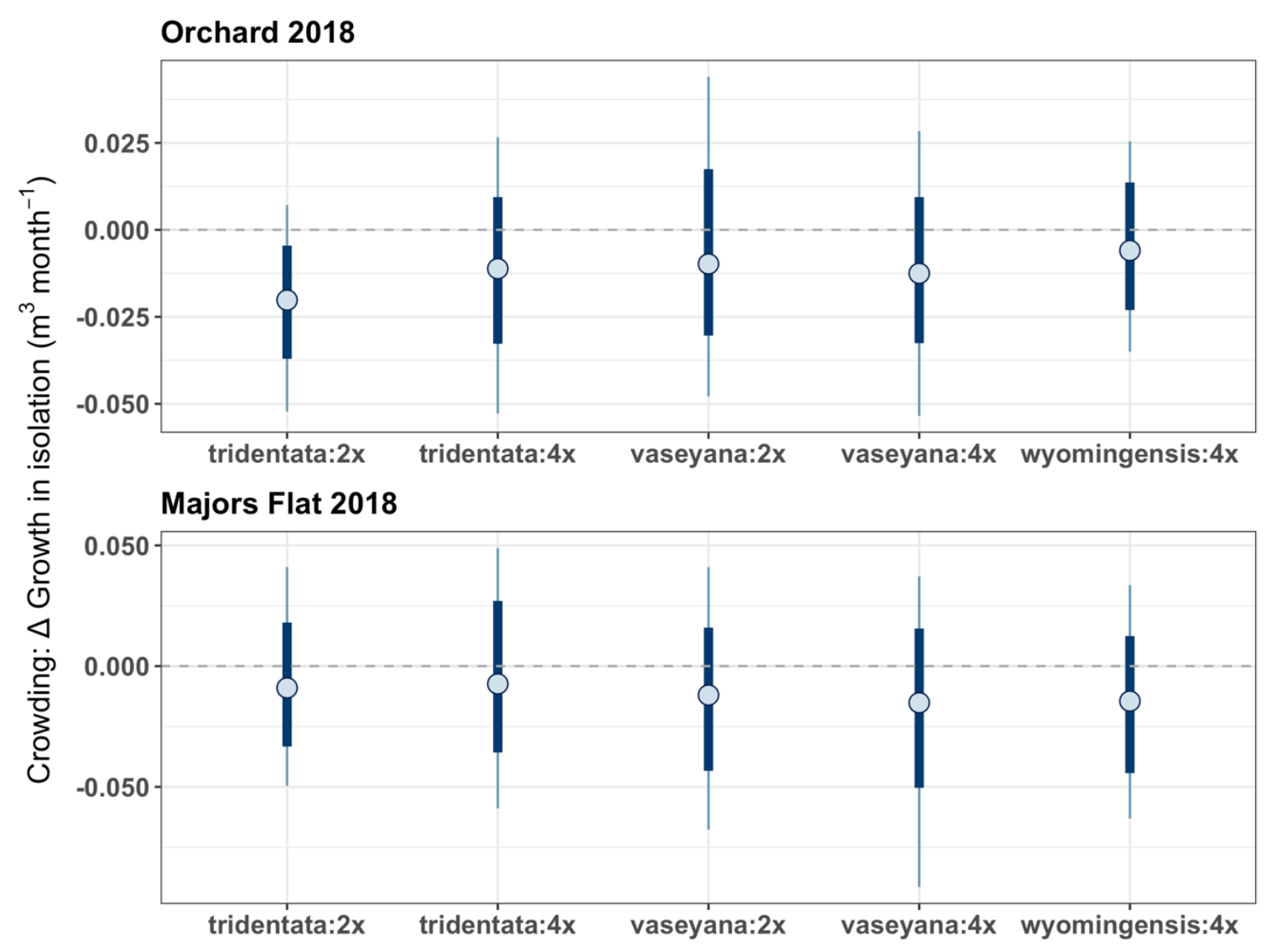

Figure S4: Posterior samples that represent the crowding effect on the relative growth rates of $A$. tridentata in two common gardens using 2018 census interval. Thick lines represent $80 \% \mathrm{CI}$, while thinner lines indicate $95 \% \mathrm{CI}$, and the dots are the medians of the posterior samples. The $x$ axis represents five subspecies:cytotype groups of $A$. tridentata. The effect size corresponds to the change in RGR when the calculated competitive pressure increases by 2 SD. Values of zero correspond to the change in RGR of a target plant under the average competitive pressure. 


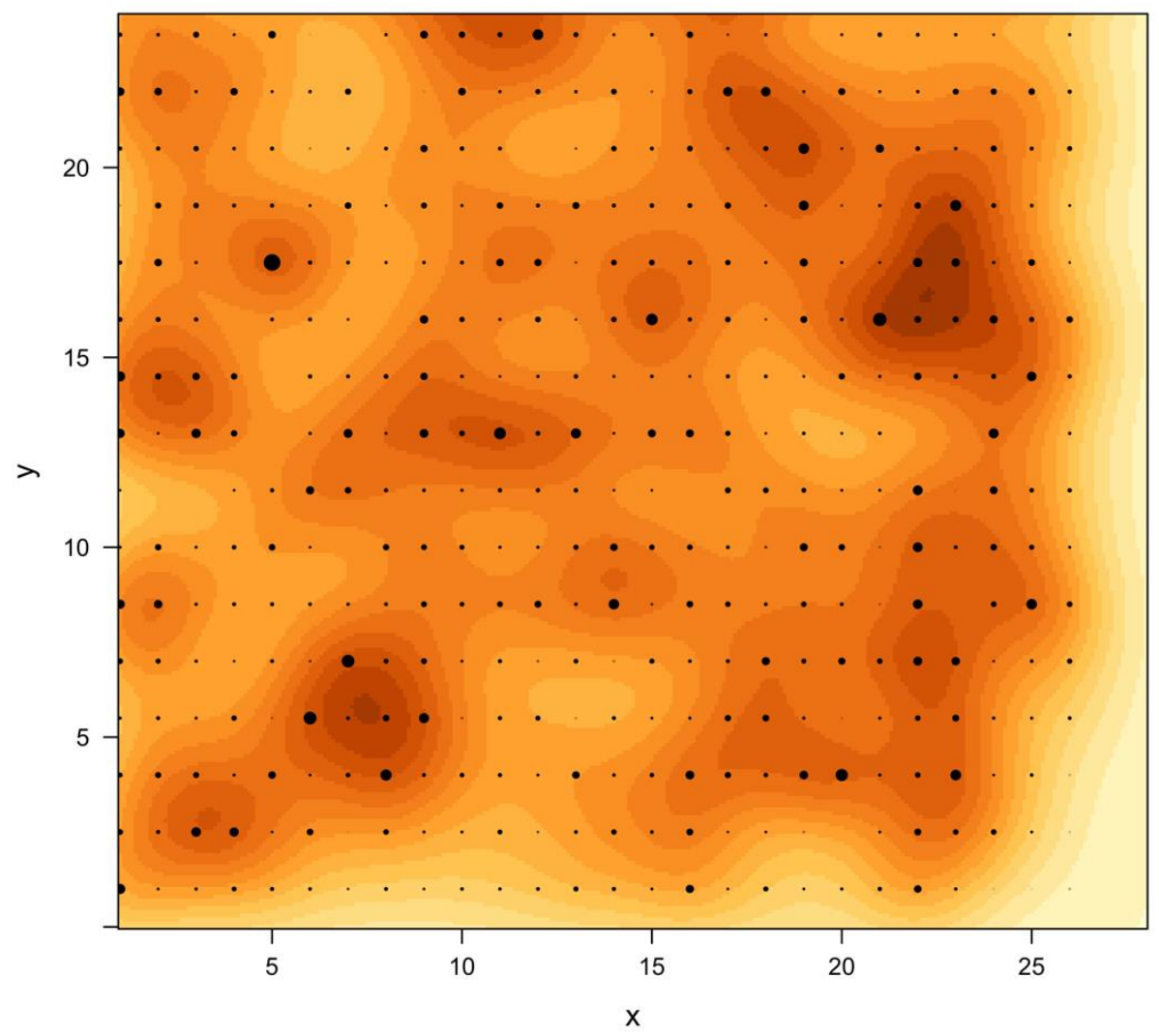

Figure S5: Mapped competition effect on A.t. tridentata:2x in Majors Flat common garden based on 2011 census interval. Dark colors indicate higher predicted competition effect, and the dots represent sagebrush plants with the relative crown size corresponding to the size of a point. The axes show $x$ and $y$ coordinates in meters. 
APPENDIX B

Supplementary Figures: Chapter Two 


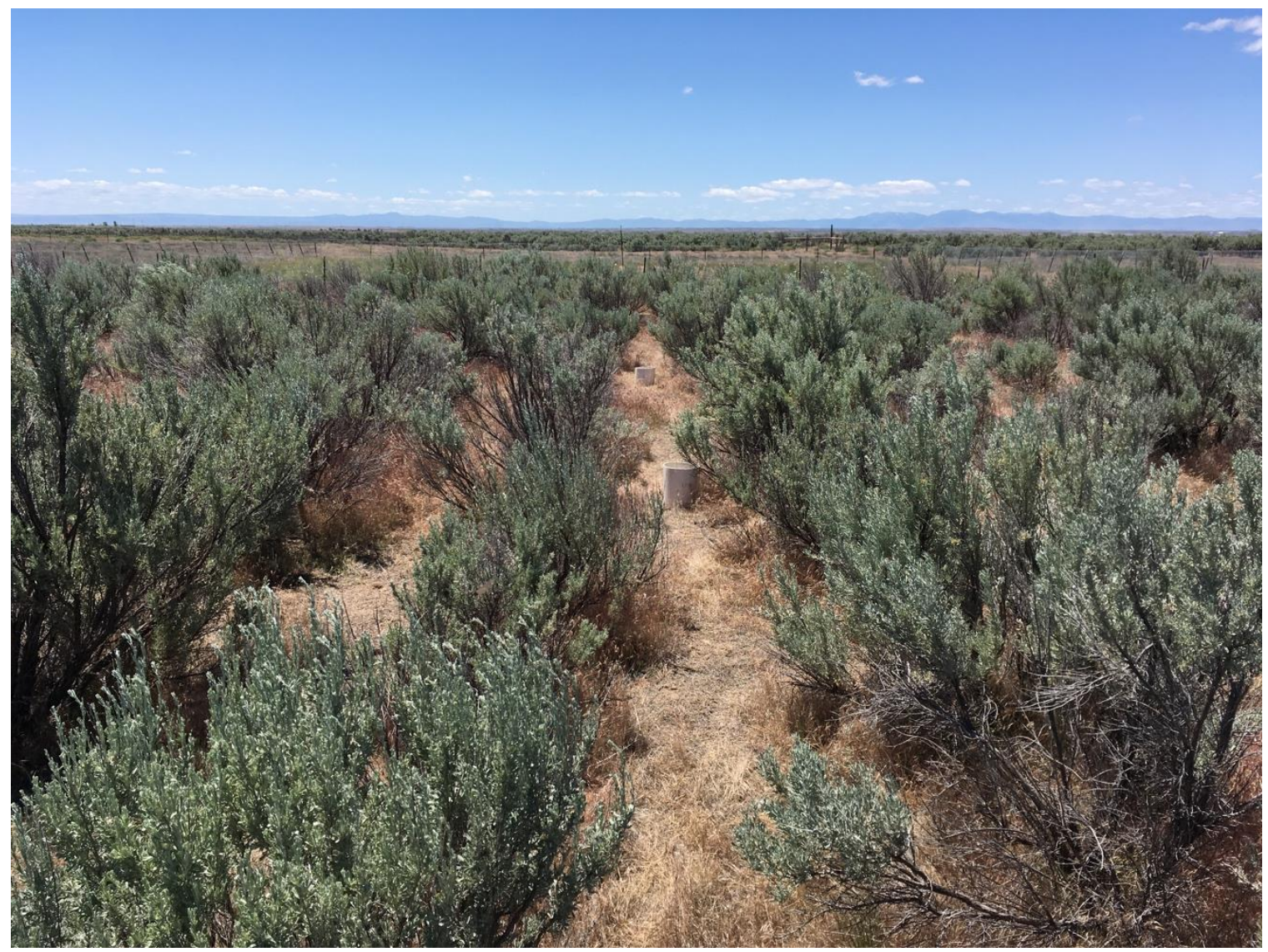

Figure S6: Big sagebrush (Artemisia tridentata) in Orchard common garden, ID. The photograph shows the spatial arrangement and individual variation in size and survival of A. tridentata. 


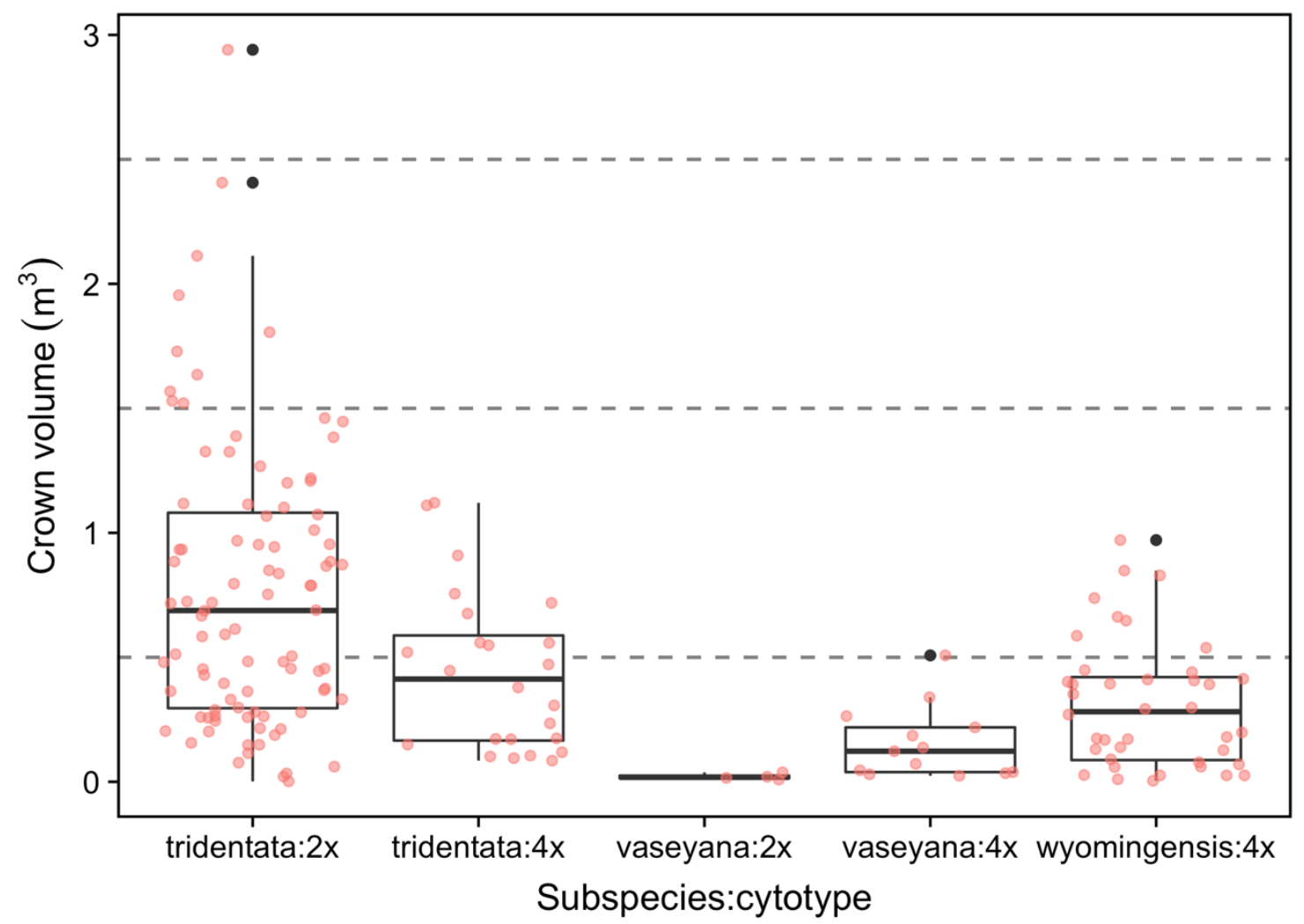

Figure S7: A box plot showing crown size distribution of $A$. tridentata in Orchard common garden. Measurements represent the data collected in summer 2018. The original crown dimensions were transformed to crown volume. The actual data points (pink dots) are jittered over the standard boxplots. 


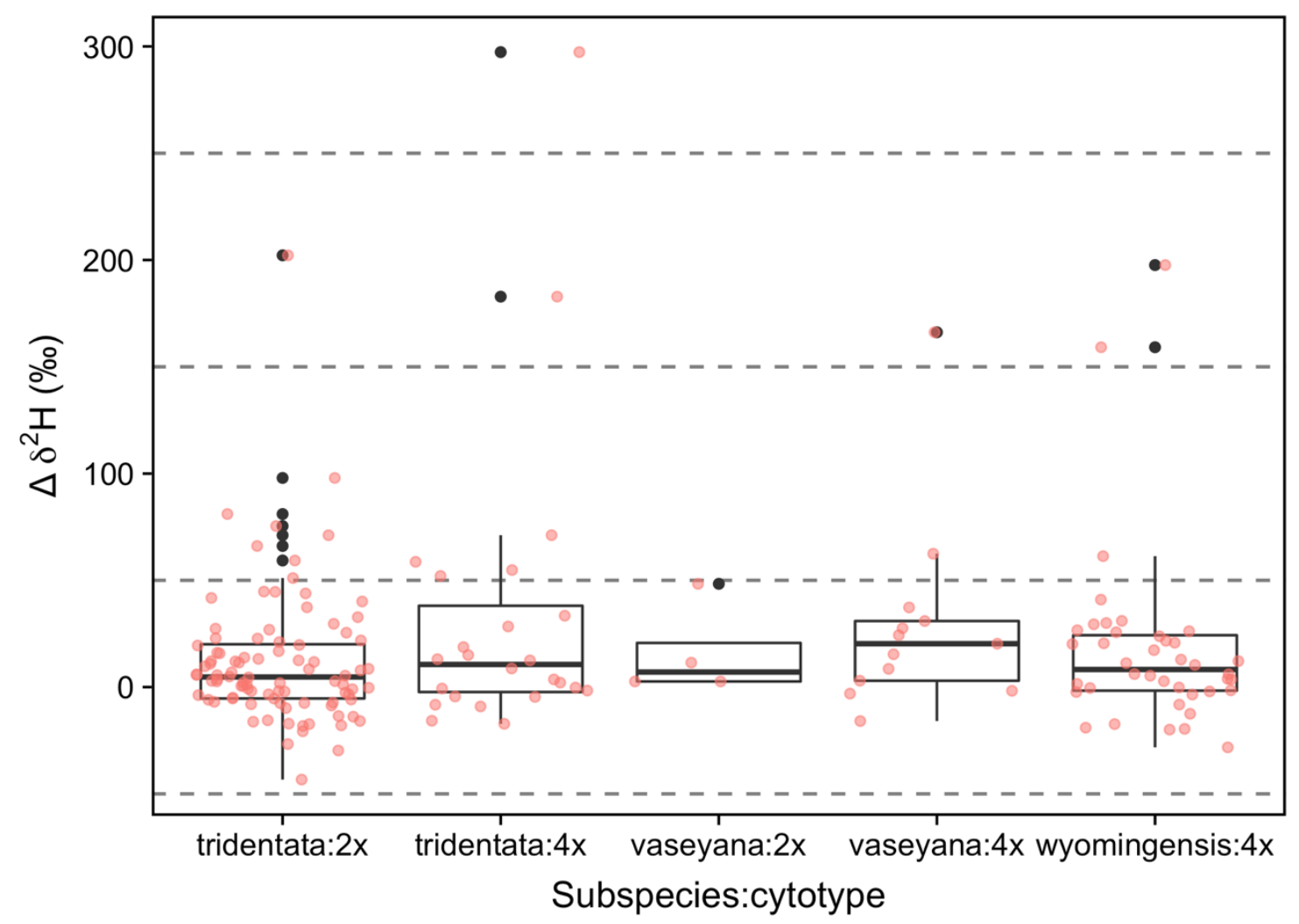

Figure S8: A box plot indicating deuterium uptake by big sagebrush individuals in Orchard common garden. The label uptake is calculated as the difference between the pre- and post-treatment deuterium measurements, and is shown for five subspecies:cytotype categories. The actual data points (pink dots) are jittered over the standard boxplots. 


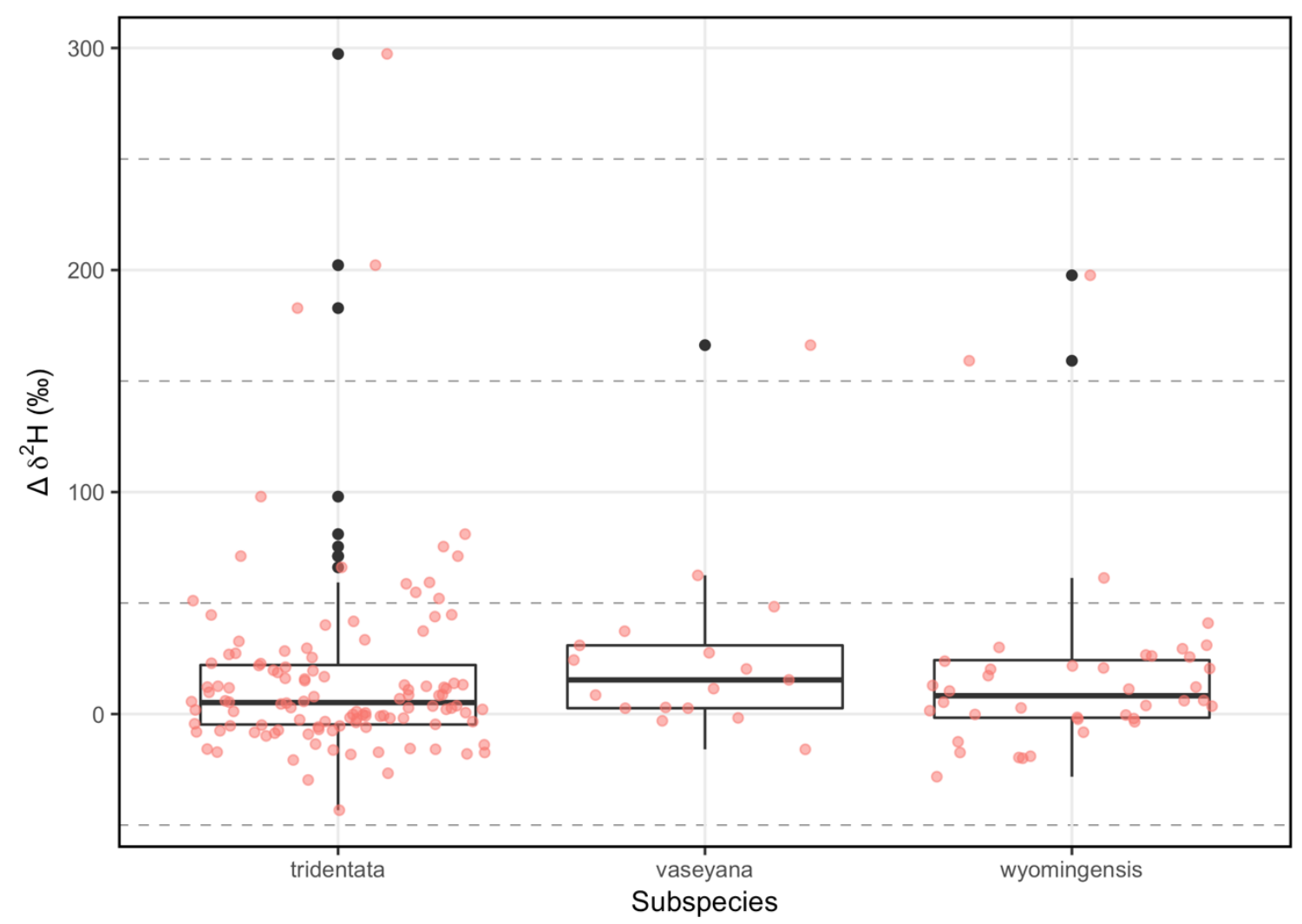

Figure S9: A box plot indicating deuterium uptake by three subspecies of big sagebrush in Orchard common garden. The uptake is calculated as the difference between the pre- and post-treatment deuterium measurements. The actual data points (pink dots) are jittered over the standard boxplots. 